University of San Diego

Digital USD

2006-04-01

\title{
Changes in Functional Status of Home Health Cardiac Patients from Admission to Discharge
}

Mary Rita McGoldrick PhD, MPH, MSN, RN, ANP-BC

University of San Diego

Follow this and additional works at: https://digital.sandiego.edu/dissertations

Part of the Nursing Commons

\section{Digital USD Citation}

McGoldrick, Mary Rita PhD, MPH, MSN, RN, ANP-BC, "Changes in Functional Status of Home Health Cardiac Patients from Admission to Discharge" (2006). Dissertations. 338.

https://digital.sandiego.edu/dissertations/338

This Dissertation: Open Access is brought to you for free and open access by the Theses and Dissertations at Digital USD. It has been accepted for inclusion in Dissertations by an authorized administrator of Digital USD. For more information, please contact digital@sandiego.edu. 
TITLE PAGE DISSERTATION

UNIVERSITY OF SAN DIEGO

Hahn School of Nursing and Health Science

DOCTOR OF PHILOSOPHY IN NURSING

\title{
CHANGES IN FUNCTIONAL STATUS OF HOME HEALTH CARDIAC \\ PATIENTS FROM ADMISSION TO DISCHARGE
}

By

Mary Rita McGoldrick, MPH, MSN, RN, ANP-BC

\author{
A dissertation presented to the \\ FACULTY OF THE HAHN SCHOOL OF NURSING AND HEALTH SCIENCE \\ UNIVERSITY OF SAN DIEGO \\ In partial fulfillment of the \\ Requirements for the degree \\ DOCTOR OF PHILOSOPHY IN NURSING
}

April 2006

Dissertation Committee

Cynthia D. Connelly, PhD, RN

Jane Georges, $\mathrm{PhD}, \mathrm{RN}$

Linda D. Urden, DNSc, RN, CNA-BC 


\begin{abstract}
The purpose of this research is to examine the functional status (ADLs and IADLs) in patients with a primary/secondary diagnosis of cardiac disease in the home health setting. The independent variables of dyspnea and service were examined for the effect on discharge functional status while controlling for the effects of age, gender, race, admission functional status, primary and secondary diagnosis. A descriptive correlational, non-experimental study of cardiac patients in an urban home health agency from January 2003 to December 2004 was conducted using data collected through a retrospective chart review. Seventeen areas of OASIS (ADL and IADL) were assessed for changes in function in this study. The null hypothesis that Home Health Care does not effect a change in functional status for cardiac patients was not supported. A paired $t$ test was conducted for the total admission functional score and the total discharge functional score. The mean difference in the scores was found to be significant with a $t$ score of $-11.094(\mathrm{p}=0.000)$, thus patient's functional status improved from admission to discharge. In the standard multiple regression, $\left(F(D F=160)=24.271, p<0.001, R^{2}=\right.$ .645) the independent variables significantly predicts the dependent variable. A stepwise multiple regression was conducted next to determine which specific independent variables made meaningful contributions to the overall predictions. The biggest contributions to discharge functional scores was admission functional score, $R^{2}=.64$, $R^{2}{ }_{a d j}=.619, F=24.271, p<.05$. With the addition of dyspnea at admit the $R^{2}$ increased to $.620, R^{2}$ change $=.019, \mathrm{~F}=6.451, p<.05$. It is interesting to note that age, gender, ethnicity, diagnosis, or service were not significant for discharge functional status scores.
\end{abstract}




\section{DEDICATION}

This dissertation is dedicated to my mother, father, and husband:

My parents, Mary F. McGoldrick and Reaves P. McGoldrick, who instilled in me the thirst for knowledge.

My husband, Dr. Karl Hasel, who has encouraged and supported me during this long and arduous journey towards a PhD. Thank you for being the best husband. 


\section{Acknowledgement}

I would like to express my sincere appreciation and thanks to those individuals who supported me during this endeavor.

To my dissertation committee

Dr. Cynthia Connelly, my chair extraordinaire, who encouraged, supported and believed in me. I cannot express my gratitude in words, you are the "gold standard" for the profession of nursing education.

Dr. Jane Georges, who adapted to a new committee seamlessly, for her expertise and encouragement.

Dr. Linda Urden, for her support, expertise, and encouragement.

To Dr. Patricia Roth, for her encouragement, support, and expertise during my sojourn in the PhD program at University of San Diego.

To Sri Gopal and the staff at Excel Home Health for their graciousness, assistance and encouragement, in allowing me to gather data at this facility.

To Angelina Carmazzi Sawitsky for her knowledge and assistance in SPSS. 
Abstract

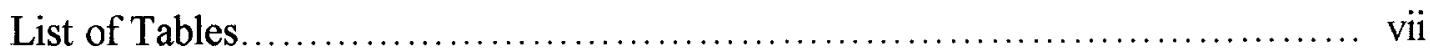

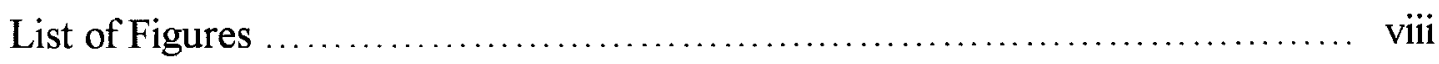

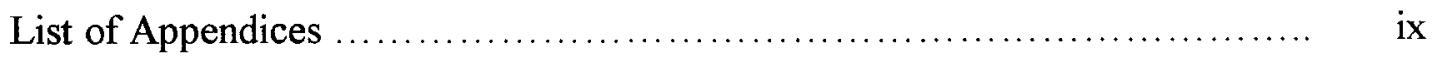

Chapter

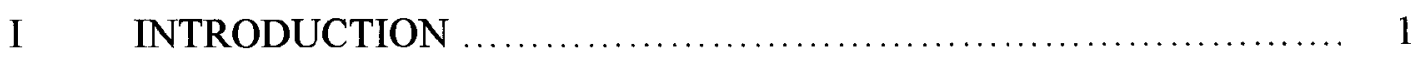

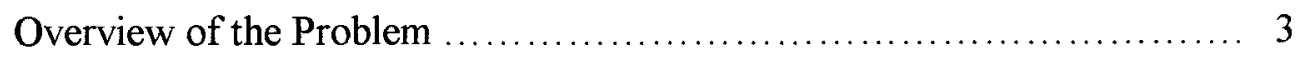

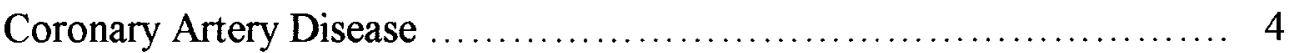

Functional Status .............................................. 5

Conceptual Framework $\ldots \ldots \ldots \ldots \ldots \ldots \ldots \ldots \ldots \ldots \ldots \ldots \ldots \ldots \ldots, 6$

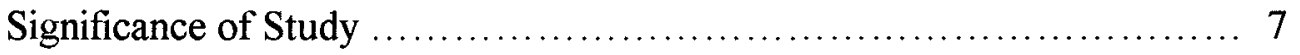

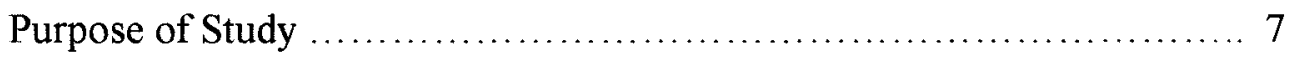

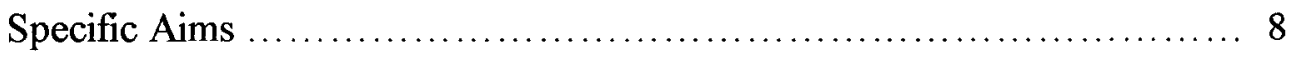

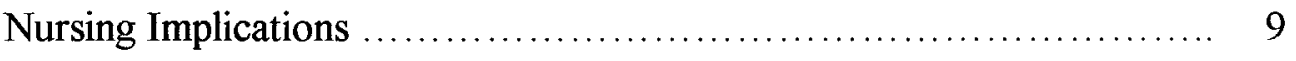

II REVIEW OF LITERATURE $\ldots \ldots \ldots \ldots \ldots \ldots \ldots \ldots \ldots \ldots \ldots \ldots \ldots \ldots \ldots \ldots$

Conceptual Framework: Quality Health Outcomes Model ............. 11

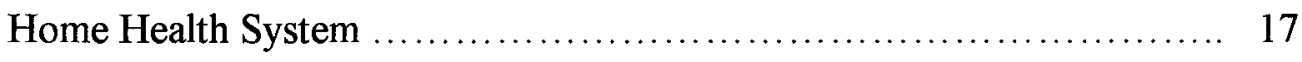

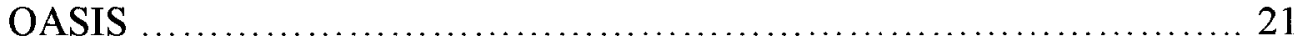

iv 
Interventions

Home Care Intervention............................... 22

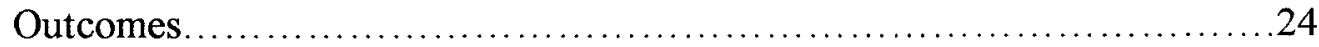

Effectiveness of Home Health Care ....................... 24

Specialized Home Care Interventions $\ldots \ldots \ldots \ldots \ldots \ldots \ldots \ldots \ldots .31$

OASIS for Measurements $\ldots \ldots \ldots \ldots \ldots \ldots \ldots \ldots \ldots \ldots \ldots \ldots \ldots$

Limitations to use of OASIS ................................. 53

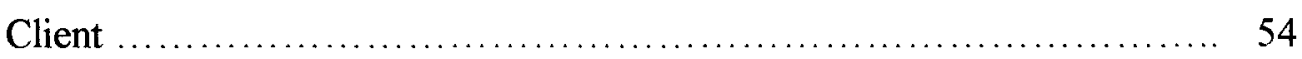

Cardiac Patients and Functional Status ................... 54

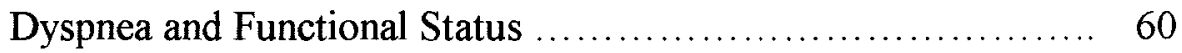

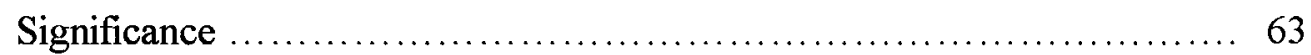

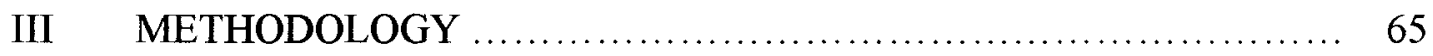

Research Design .............................................. 65

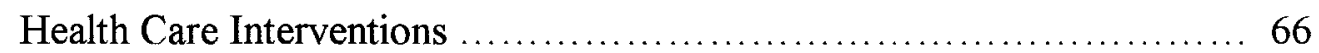

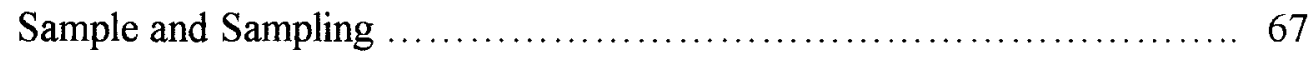

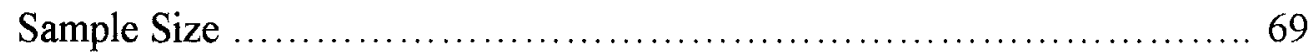

Data Collection Procedures ......................................... 69

Measurements ................................................ 70

Dependent Variable .......................................... 71

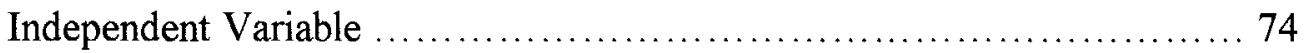

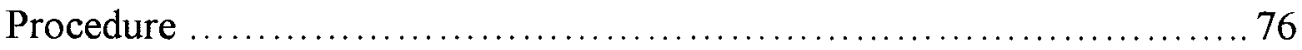


Date Analysis

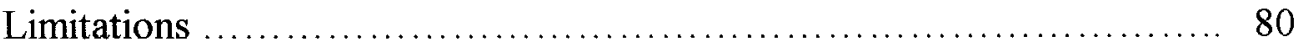

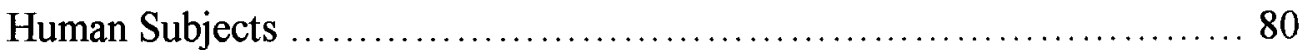

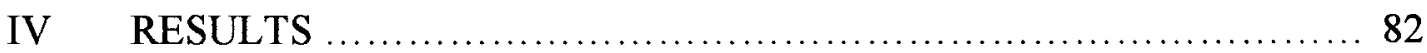

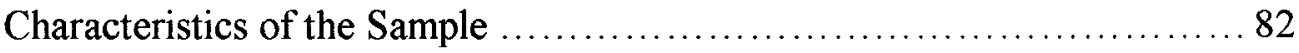

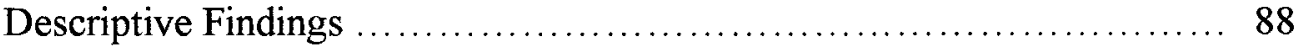

Findings related to hypothesis testing $\ldots \ldots \ldots \ldots \ldots \ldots \ldots \ldots \ldots \ldots \ldots \ldots$

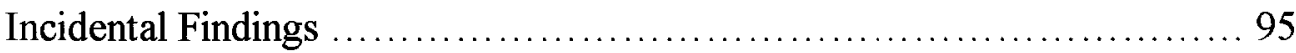

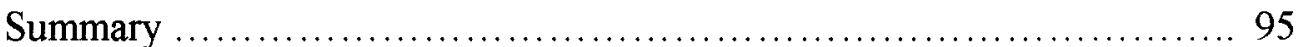

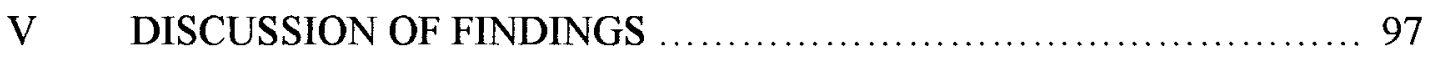

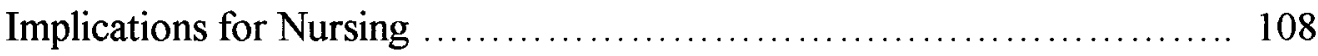

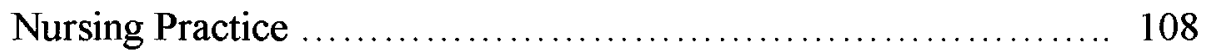

Nursing Education ........................................ 109

Nursing Research ..................................... 109

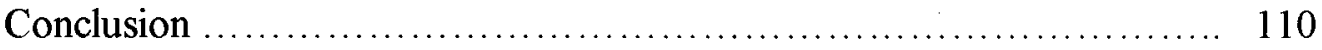

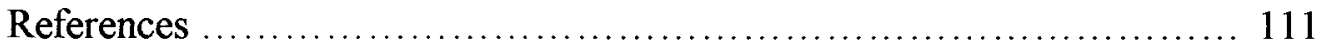

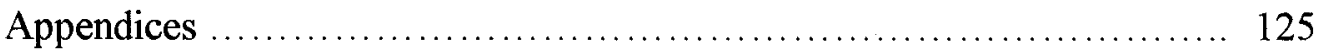


List of Tables

Table

1. Dyspnea and Functional Status

2. OASIS: Patient Functional Status Items.

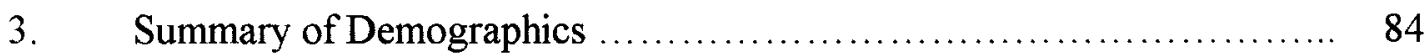

4. Means and Standard Deviation : Medications \& Service ................ 87

5. T-Test for admit/discharge functional status ........................ 89

6. Pearson Product Moment Correlations Coefficients between

functional status at admission, dyspnea, service, primary diagnosis, secondary diagnosis, age, gender, race, and the dependent variable discharge functional status

7. Pearson Product Moment Correlations Coefficients between functional status at admission, dyspnea, service, primary diagnosis, secondary diagnosis, age, gender, race 92

8. Model Summary Coefficients for Simultaneous Multiple Regression Analysis 93

9 Model Summary using Stepwise Multiple Regression Model 94.

vii 


\section{List of Figures}

Figure Page

1. Quality Health Outcomes Model ............................... 15

viii

Reproduced with permission of the copyright owner. Further reproduction prohibited without permission. 
List of Appendices

Appendix

Page

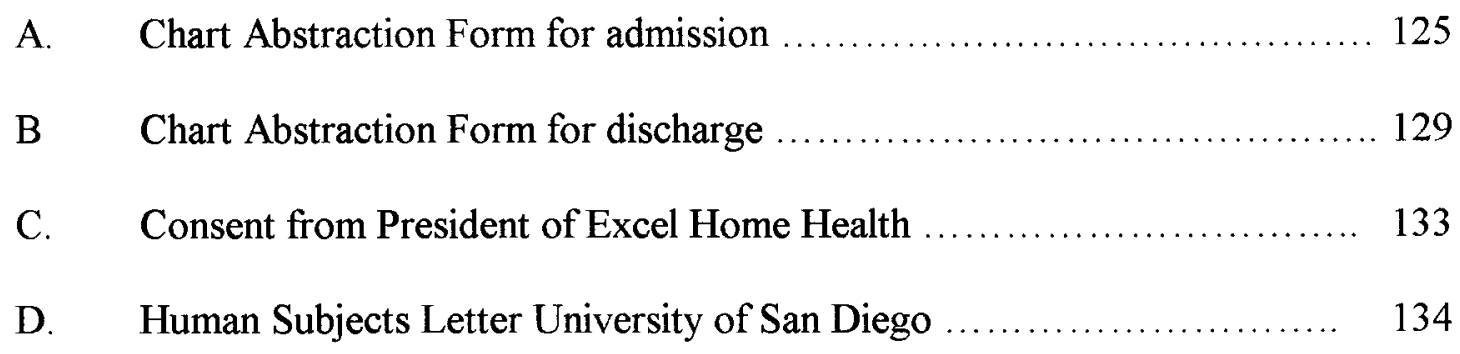

ix 


\section{CHAPTER 1}

\section{Introduction}

The use of home health care services, especially for the elderly, has increased dramatically in recent years. This trend has been prompted by the increased public funding for home care, shortened hospital stays that often result in a need for follow up care, advances in medical technology that facilitate home care treatment, and the desire of individuals to continue living in their home rather than having to move in order to receive services (Coleman, 2000).

Home health care services include skilled nursing care, physical therapy, occupational therapy, speech therapy, and personal assistance with basic activities of daily living, such as bathing and dressing, or a combination of skilled and personal care (Coleman, 2000). Home health care interventions may have a single discipline involved or multiple disciplines treating and teaching the patient. To be referred to a Medicare certified home health agency the patients must have a precipitating event in their health status. A precipitating event means either the patient has been hospitalized or there has been a change in health status requiring the skilled need of a Registered Nurse ( $R N)$, Physical Therapist (PT), or Speech Therapist (ST). Generally it is the RN who is the 
first discipline to see and assess the patient. Depending on her/his assessment, and with the agreement of the physician, referrals to other disciplines are initiated. This means that nurses and therapists must have an extensive working knowledge of psychosocial and environmental factors that may be barriers to the medical care plan. In consultation with the physician each discipline determines the frequency and duration of home care visits (OASIS, 1998).

Nursing visits are the most common service in home health care, followed by home health aides and therapy (physical and occupational). Patients are seen frequently at the start of care, sometimes daily or even twice daily, but the intensity rapidly tapers as patients improve (Smith, Cowan, Sensenig, \& Catlin, 2005). Care is given on an intermittent basis rather than long term or convalescent care, with services provided to patients in their homes. Home-health nurses care for a broad range of patients, such as those recovering from illnesses and accidents, cancer, and dementia. Currently, home health RNs are providing care at home for new or recurrent problems that would have resulted in a hospitalization just a few years ago (Mezey \& McGivern, 1999). Home health care consists of assessment of the patient status, administration of medication, performance of procedures, and teaching/instruction to the patient or caregiver about their disease process and prevention of exacerbation of the disease process (Mezey \& McGivern, 1999; Murkofsky, Phillips\& McCarthy, 2003). Additional service referrals initiated by the physician and nursing may include a home health aide, physical therapy, occupational therapy, speech therapy and social work. 


\section{Overview of the Problem}

The National Center for Health Statistics conducted a survey in 2000 and found that at any one time approximately $1,263,100$ patients were receiving home health care (National Center for Health Statistics, 2005). Of the 1,263,100 patients, 842,600 required assistance with functional status (National Center for Health Statistics, 2005) The cost to society is staggering, the national health spending was 1.7 trillion in 2003 and of the 1.7 trillion dollars, 40 billion dollars was spent on home health care (Smith, Cowan, Sensenig, \& Catlin, 2005).

The growth of the home care industry has been accompanied by concerns about the quality of care provided. Recently, policymakers and regulators have questioned if public monies are paying for effective services that result in better health or improved functioning for the consumer. Prior to 2000 each home health agency reviewed it's own data to determine if services were appropriate for patient care. As pointed out by Gingerich and Ondeck (1999) outcomes measurement within home care was individualized according to the organization or system; there was no universal process for measurement and comparison of outcomes. The Institute of Medicine (IOM) has defined quality of care as "the degree to which health services for individuals and populations increase the likelihood of desired health outcomes and are consistent with current professional knowledge (Mitchell, Ferketich, \& Jennings, 1998). Thus, as argued by Mitchell and Lang (2004), to evaluate the effectiveness of home care it is necessary to measure client outcomes associated with healthcare. In other words, the effectiveness of home care can be measured by improvement of patient outcomes such as healing of wounds, increase in functional status, or understanding of his/her disease process. 
In the year 2000, the Center for Medicare and Medicaid (CMS) mandated the application of the Outcome Assessment and Information Set (OASIS) both as a basis for reimbursement and to establish national outcomes. All Medicare home health agencies have their outcomes compared to their scores from the previous quarter and nationally against other home health agencies. These scores or outcomes are an aggregate of all the patients within the home health agency. A review of the literature found no one has deaggregated the scores to determine outcomes for specific patient groups such as disease process, age, or gender. Rather each home health agency's aggregate scores are posted on the Internet for consumers, discharge planners, and physicians to compare and shop for home health agencies. Agencies are required to improve their outcomes in total rather than looking at specific disease process, the age of the patients, or other individual criteria that might represent barriers to improvement in overall outcomes.

\section{Coronary Artery Disease}

Coronary heart disease (CHD) is the leading cause of death in adults in the United States. An estimated 13.7 million people have coronary heart disease, one half of whom has had an acute myocardial infarction and the other half has angina pectoris. According to the American Heart Association (2004), about every 29 seconds someone in the US suffers from a CHD-related event, and approximatley every minute someone dies from such an event. The lifetime risk of having coronary heart disease after age 40 is $49 \%$ for men and $32 \%$ for women. As women get older, the risk increases almost to that of men (Banchard, Rodgers, \& Daub, 2002). One million new or recurrent coronary events were expected in the Unites States in the year 2000 and the American Heart Association (2004) states that 1.5 million persons will have a new or recurrent event in 
the year 2004. The National Center for Health Statistics (2005) determined that of the $1,232,200$ patients receiving Medicare certified home care at one point in time, $10 \%$ of the those patients had heart disease, the second largest group of patients receiving home health; the largest group ( $23 \%$ of the home care population) are patients with diseases of the circulatory system (National Center for Health Statistics, 2005).

Congestive heart failure (CHF) is disturbingly common. It affects approximately 4.8 million people in the U.S. and becomes more common with advancing age. The wellknown Framingham heart study found that an average of 3.7/1000 men and 2.5/1000 women are diagnosed yearly with cardiac failure. This means that over 400,000 new cases of heart failure are diagnosed each year in the U.S. with Americans spending over 17 billion dollars annually on treatments for CHF (American Heart Association, 2004).

Normal aging changes and health problems, such as $\mathrm{CHD}$, frequently show themselves as declines in the functional status of older adults. One of the best ways to evaluate the health status of older adults is through functional assessment, which provides objective data that may indicate future or present decline or improvement in health status (Shelkey \& Wallace, 1998). Functional status is a key element of healthcare practice and must be incorporated as outcome criteria.

\section{Functional Status}

As America's elderly population grows, improving and or maintaining their functional status becomes an increasing challenge. Geriatric assessments place high value upon functional status, both as a dimension to be evaluated and as an outcome to be improved or maintained (Hazzard, Blass, Halter, Ouslander, \& Tinetti, 2003). Treatment for all home health patients has the optimal goal of returning patients to, or maintaining 
them at, their highest possible level of self-care and independent functioning. Whether patients are convalescing from an acute illness or suffering chronic impairment, home health treatment is aimed at allowing them to return to or remain at home, and receive treatment outside of an institutional setting. Prior research has shown functional status and perceived quality of life are highly associated in the elderly (Patrick, Kinne, Engleberg, \& Pearlman, 2000). Thus the measure of overall functional ability and independence are important ways to assess the efficacy of home health treatment (Keepnews, Capitman, \& Rosati, 2004; Patrick, Kinne, Engleberg, \& Pearlman, 2000).

\section{Conceptual Framework}

To understand the relationship between home health and function status of CAD patients, the Quality Health Outcomes Model (QHOM) as a conceptual framework was used. QHOM posits reciprocal interaction among 4 constructs: system characteristics, interventions, client characteristics, and outcomes. Outcomes of patient care or health delivery interventions in institutions and the community are mediated and moderated by characteristics of the care system and of the client. The traditional elements of structure are measured as part of the system of care; the processes (such as home care services) can be directly measured as specific interventions or as system processes (Mitchell, Ferketich, \& Jennings, 1998). The QHOM deals with human-environment interactions that influence the effect of nursing interventions on client outcomes.

The QHOM addresses the four concepts of the nursing meta-paradigm identified by person, environment, health, and nursing. The meta-paradigm concept person is evident in the QHOM concept of client characteristics and environment is evident in healthcare system characteristics identified in QHOM. The concept of health is implied 
in the QHOM concept of outcomes in as much as outcomes address client's wellness and or illness levels. Finally the concept nursing is evident in the QHOM concept of interventions. The QHOM can therefore be used to guide nursing discipline-specific research; it can also be used to guide multidiscipline research (Radwin \& Fawcett, 2002).

\section{Significance of Study}

Although home health services have been advocated as an ideal intervention to return and maintain patients at their highest self-care, independent function, few programs have been rigorously evaluated. The OASIS was developed in response to the mandate to measure client outcomes associated with home health care. This instrument provides aggregate client data to evaluate agency outcomes with the expectation to improve their total rather than specific client need. Home health care may not however be effective for all; rather it may be more appropriate to examine disease specific improvement. To date, however, no studies have been conducted on de-aggregation for specific groups such as disease process. This study is an attempt to fill this gap; the relationship of home health services, cardiac disease, and functional status was examined.

\section{Purpose of the Study}

The QHOM model is being used in this study because it suggests that client intervention, client characteristics, as well as, system characteristics effect outcomes. Patients with heart disease are being examined, first because they represent a large percentage of the home health patient population and second to determine if home health interventions effects change in patient's functional status. Functional status is being chosen as the dependent variable because the literature suggests that maximizing functional status enables people to live independently (Benjamin, 1999). 
The OASIS provides an excellent source for outcome data for two reasons: First, it has been developed as an outcome measurement tool specifically designed for use with home health patients and second, it is now mandated by CMS for use by all Medicare and Medicaid certified home health agencies. The OASIS is used to score the 17 quality indicators as an aggregate and this study will look at one diagnostic group for improvement in functional status.

The purpose of this proposed study is to examine the relationship of home health care to functional status, represented by activities of daily living (ADLs) and instrumental activities of daily living (IADLs), in patients with a primary and or secondary diagnosis of cardiac disease. In addition, the variables of dyspnea and service will be examined for their relationship to home health care and functional status outcomes.

\section{Specific Aims}

The three specific aims relevant to this study:

Aim \#1: Examine functional status in patients with a primary/secondary diagnosis of cardiac disease from admission to discharge in the home health setting.

Aim \#2: Examine the relationship between the independent variables of age, gender, ethnicity, primary diagnosis, secondary diagnosis, admission functional status dyspnea, service and the dependent variable of discharge functional status.

Aim \#3: Examine the effect of the dyspnea and service on functional status in patients with the primary/secondary diagnosis of cardiac disease at discharge in the home health setting. 


\section{Nursing Implications}

Home health care services include skilled nursing care, physical therapy, occupational therapy, speech therapy, and personal assistance with basic activities of daily living, such as bathing and dressing, or a combination of skilled and personal care (Coleman, 2000). Home health care interventions may have a single discipline involved or multiple disciplines treating and teaching the patient. Generally, it is the RN who is the first discipline to see and assess the patient. Depending on her/his assessment, and with the agreement of the physician, referrals to other disciplines are made (OASIS, 1998).

Home health RNs provide care at home for new or recurrent problems that would have resulted in a hospitalization just a few years ago (Mezey \& McGivern, 1999). Home health care consists of assessment of the patient status, administration of medication, performance of procedures, and teaching/instruction to the patient or caregiver about their disease process and prevention of exacerbation of the disease process (Mezey \& McGivern, 1999; Murkofsky, Phillips, \& McCarthy, 2003). Additional services referred by the physician and nursing may include a home health aide, physical therapy, occupational therapy, and speech therapy.

The registered nurse plays a pivotal role in determining the interdisciplinary team and directing the team towards common goals. The $\mathrm{RN}$, as the team leader, is constantly assessing patient status during the home visits; she is looking at the whole patient, whereas each discipline is concentrating on their specific role. The $\mathrm{RN}$ as the team leader listens during interdisciplinary conference about the progress of the patient from each discipline and makes important decisions on patient care. Additional knowledge on 
improving functional status for the home health patient can assist the $\mathrm{RN}$ in her repertoire of skills to care for home health patients. Functional status and perceived quality of life are highly associated in the elderly, thus the measure of overall functional ability and independence are important ways to assess the efficacy of home health treatment (Keepnews, Capitman, \& Rosati, 2004; Patrick, Kinne, Engleberg, \& Pearlman, 2000). 


\section{CHAPTER 2}

\section{Review of Literature}

The accelerating growth in the provision of home health services is accompanied by the need to demonstrate desired health outcomes consistent with professional knowledge. The national outcomes and assessment information set (OASIS) can compare various home care facilitated outcomes, and scholarly inquiry is needed to examine outcomes by disease category. In this chapter the Quality Health Outcomes Model, the guiding framework for this study, will be discussed. The four concepts within this model (client, system, intervention, and outcomes) will be described with a presentation of the literature pertinent to these concepts. The health outcomes of functional status of cardiac patients within this context will be explored with the identification of variables associated with functional status discussed. Finally gaps in the literature and need for further research is presented.

\section{Conceptual Framework: Quality Health Outcomes Model}

In 1998 the expert Panel on Quality Health Care of the American Academy of Nursing published the Quality Health Outcomes Model (QHOM) as a conceptual framework for quality and outcomes research, most specifically as a means to test 
relationships among the elements of structure, process, and outcomes. The academy model built on Donabedian's classic structure - process- outcome framework for quality health care and Holzemer's three-dimensional expansion of the Donabedian triad to include multiple level analyses among client, provider, and setting (Mitchell, Ferketich, \& Jennings, 1998).

The three elements of quality first proposed by Avedis Donabedian are structure, process, and outcome. Quality of health care structure refers to the quality of the facilities and the environment in which health care is provided: buildings, equipment, and degree of training of health care professionals. Quality of health care process refers to the correctness and appropriateness of the actual care that is provided: decisions concerning an indication to operate, how the operation was carried out. Quality of health care outcomes refers to the actual result of the care provided: improved health, patient satisfaction, and reduced pain (Donabedian, 1966).

Holzemer's (1994) expansion of the Donabedian triad proposes a multilevel assessment of outcomes. Holzemer's “Outcomes Model for Healthcare Research" suggests that outcomes are derived from the assessment of client, provider and setting. Working toward optimal health is the primary health care service goal taking into account client preferences. However, the concept is not operationalized well and therefore not easily measured. Variables that indicate client health outcome change include health status, health knowledge, health behavior, and satisfaction with health care. The health status category is divided further into physical, social, psychological, and general domains. The physical domain includes physical function, symptoms, and impairments. The social domain comprises role and social function. The psychological domain 
subsumes cognitive function and psychological well-being. The general health domain incorporates concepts that cross more than one domain such as quality of life. Health knowledge is the ability to remember and interpret information and health behaviors are the observable responses, actions, or activities fitting the occasion or purpose. Satisfaction with health care such as providers or setting is a major indicator of quality of care. Clients' ability to recognize interpersonal and technical aspects of their care is acknowledged by many (Holzemer, 1994).

Clinical and functional outcomes are integrated into the Quality Health Outcomes Model but the path from interventions to outcomes in the model was conceived as being mediated and moderated by both system and client characteristics. Five outcome categories hypothesized as sensitive to nursing care inputs were recommended: achievement of appropriate self-care, demonstration of health promoting behaviors, health related quality of life, perception of being well cared for, and symptom management (Mayberry \& Gennaro, 2001; Mitchell, Ferketich, \& Jennings, 1998).

The Quality Health Outcomes Model posits reciprocal interaction among 4 constructs: system characteristics, interventions, client characteristics, and outcomes. Examples of these would be the home health agency, home health interventions, home health patients and improvement in functional status as the outcome. Outcomes of patient care or health delivery interventions in institutions and the community are mediated and moderated by characteristics of the care system and of the client, with both client and care system capable of being understood and measured at multiple levels (individual through population). The traditional elements of structure are measured as part of the system of care; the processes (such as home care services) can be directly 
measured as specific interventions or as system processes (Mitchell, Ferketich, \& Jennings, 1998).

The model was developed within a socio-historical context of considerable interest in the explicit identification of the outcomes of nursing interventions as a way of advancing nursing science. Mitchell and colleagues (1998) went beyond a simple intervention-outcomes approach by proposing that interventions do not act directly on outcomes, but instead interventions are affected by and affect both client characteristics and healthcare system characteristics in producing outcomes (Radwin \& Fawcett, 2002). It is important for nursing systems research because it incorporates essential components of nursing care characterized by structures and processes that integrate functional, social, psychological, and physiological aspects of patient experiences during illness and when promoting health (Mitchell, Ferketich, \& Jennings, 1998). In particular, the QHOM deals with human-environment interactions that influence the effect of nursing interventions on client outcomes. The QHOM addresses the four concepts of the nursing meta-paradigm identified by person, environment, health and nursing. The meta-paradigm concept person, is evident in the QHOM concept of client characteristics and environment is evident in healthcare system characteristics identified in QHOM. The concept of health is implied in the QHOM concept of outcomes in as much as outcomes address client's wellness and or illness levels. Finally the concept nursing is evident in the QHOM concept of interventions. The QHOM can therefore be used to guide nursing disciplinespecific research; as well as multidiscipline research (Radwin \& Fawcett, 2002).

The model suggests that interventions are impacted by both the system (the home health agency) and the client. Outcomes are a function of client characteristics and the 
systems policies for interventions, and both the client and the system interact with each other and affect interventions and outcomes.

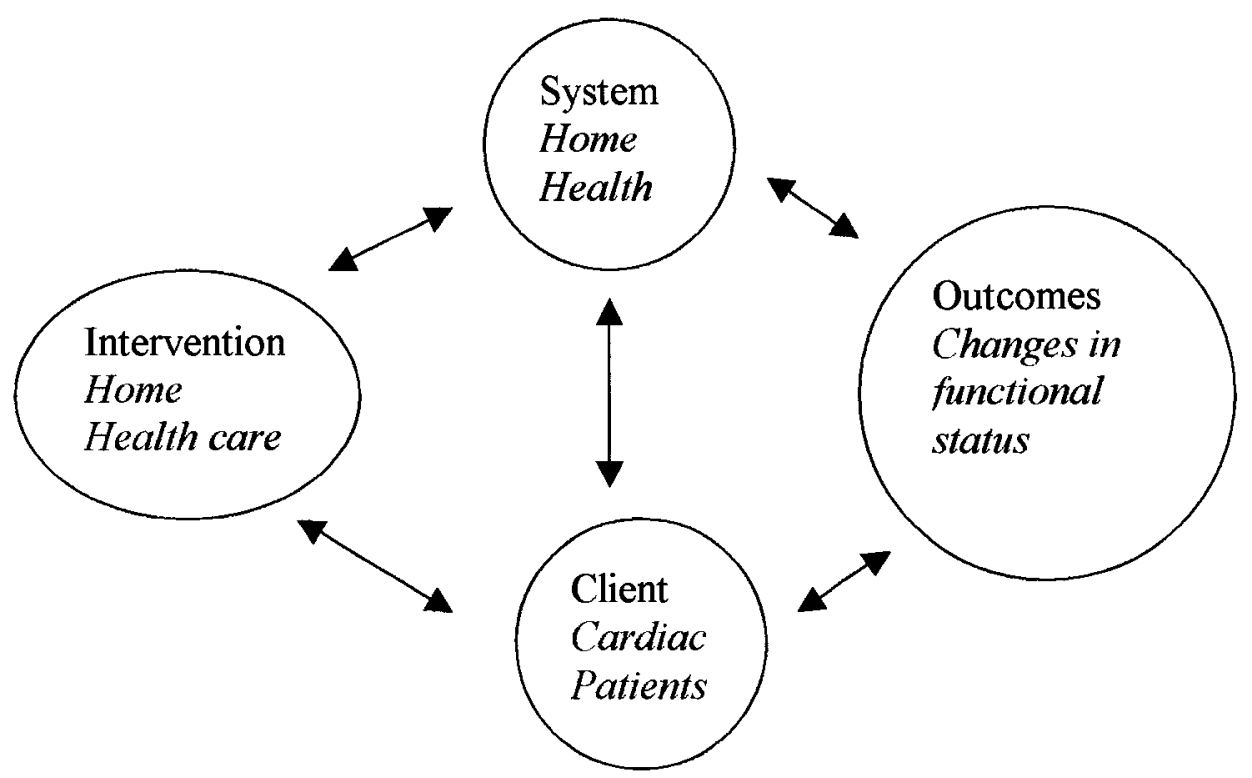

Figure 1. Quality Health Outcomes Model (Mitchell \& Lang, 2004)

Mayberry and Gennaro (2001) applied the model to a review of second stage labor in obstetric care. The purpose of their study was to identify a model that can be used to examine care in second stage labor and to describe how it can be used to develop best practice of nursing for second stage labor. Mayberry and Gennaro (2001) suggest that specific interventions such as cesarean delivery and epidural analgesia will differ in their quality outcomes depending on system (skill mix, policies) and client characteristics. They found that care of women in labor in the context of a quality of health outcomes model is an example of how to systematically organize collaborative effort of physicians, nurses, and others towards achieving health care goal. 
Radwin (2002) used the model to frame her work in identifying components of several aspects of patient characteristics, intervention, and system for care of oncology patients. She revisited her past studies and applied the QHOM. Radwin's (1989) first study focused on clinical nurse specialists' diagnostic decision making. The participants completed diagnostic tasks requiring discrimination among five pain conditions by collecting information about two hypothetical patients that were presented in comprehensive case studies. Analysis of the data revealed that some nurses accurately identified the nursing diagnosis for each pain condition and some did not. The findings suggest that improving the accuracy of nursing diagnosis could strengthen nursing interventions. Radwin's (1989) application of the concepts of QHOM identified; patient information about the pain condition can be viewed as client characteristics, and the clinical nurse specialist decision making process can be viewed as an intervention. The study contributed to nursing science by describing an empirical linkage between the metaparadigm concepts person (patient's pain conditions) and nursing (clinical decision making).

In a second study, Radwin (1995) utilized a qualitative, grounded theory methodology to describe strategies used by a purposive sample of expert nurses to make decisions about the care of acutely ill cardiac patients. The data, which included participant observation field-notes, text from semi structured interviews, and hospital records were collected at an urban teaching hospital. Analysis of the data revealed a middle range theory of expert nurses' clinical decision making, "Knowing the Patient". The process of knowing the patient is a purposeful action that the nurse uses to enhance understanding of the patient's unique experiences, behaviors, feelings, and perspective. 
This knowledge allowed the nurse to individualize the patient care. Radwin (1995) interpreted this study within the interventions and client characteristics concepts of the QHOM. The knowing the patient clinical decision making process and individualized interventions represent interventions and the patient's experiences, behaviors, feelings. Perceptions represent client characteristics.

The benefit of retrospectively fitting past studies with an explicit conceptual model is the uncovering of new possibilities. As findings from a number of seemingly disparate studies are linked together in a new way, previously unanticipated avenues for investigation are revealed.

\section{Home Health System}

The enactment of the Medicare and Medicaid programs in 1965 (Titles 18 and 19 of the Social Security Act) made public financing available for professional home health services. This laid the foundation for increased use of formal, paid home care services usually combined with informal care from family members and other unpaid caregivers (Binstock \& Cluff, 2000). Medicare home health coverage was initially authorized only as a post-hospital discharge benefit for a given number of days following the patient's discharge. The underlying notion of this benefit was that it would provide a cheaper alternative to extended hospital stays and reduce overall health care costs. Medicare home health was conceptualized as a short-term treatment for persons with rehabilitative potential rather than for long term care (Benjamin, 1993).

Coverage was provided for nursing visits, services by medical social workers, physical, occupational, and speech therapy, medical supplies and equipment, and home health aide services. Required for this coverage was a "post acute" care plan provided by 
the patient's physician, who was expected to provide ongoing medical supervision (Benjamin, 1993). Home Health care was covered under Medicare part A, which covers hospital bills. Medicare part B which covers physician bills will cover home health if the patient does not qualify for Medicare part A. Payment under Medicare part B required copay by the patient.

In 1966, slightly more than 19 million elderly persons were enrolled in Medicare. By 1973 , the inclusion of this newly eligible population swelled the ranks to 32.5 million (Jonathon, Longest, \& Darr, 1992) Increasing access to medical care was not without cost. The 1970 Medicare expenditures of $\$ 7.3$ billion rose to $\$ 36.4$ billion by 1980 , nearly doubling the percentage of the gross national product within 10 years (Conley \& Walker, 1998)

Medicare coverage for home health was expanded with the Omnibus Reconciliation Act of 1980 (OBRA) which eliminated the requirement of a prior hospitalization and removed the limitations on the number of visits for home health under Medicare Part A, eliminated the Part B deductible for home visits, and removed the restriction on certification of proprietary home health agencies (Conley \& Walker, 1998; Binstock \& Cluff, 2000). As a result, for proprietary home health agencies grew from 471 in 1982 to 1904 in 1986 (Estes, Swan, Bergthoid, \& Spohn, 1992). The Social Security Amendments of 1983 had an enormous impact on the home health industry by implementing a prospective payment system in the form of diagnostic related groups (DRGs) for hospitals. As patients were discharged from the hospital more rapidly the percent of discharged patients using home health rose from $8.9 \%$ in 1981 to $13.3 \%$ in 1985 (Estes et al, 1992). Medicare home health beneficiaries increased from 760,000 in 
1977 to $1,340,000$ in 1983 (Anderson, 2000). Medicare payments for home health increased from 0.8 billion in 1980 to 15.7 billion in 1997 (Anderson, 2000). The combined influences of OBRA of 1980, increased technology that enabled hospital treatment to be provided at home and hospital incentives for quicker discharges created an explosion in the home care industry with a rapid rise in the number of home health agencies. In 1982, the Tax Equity and Fiscal Responsibility Act authorized reimbursement for Hospice care for the terminally ill. This extended home care coverage to an additional patient population, because $78 \%$ of hospice patients are cared for at home rather than in institutions (Haupt, 1998).

Considerable liberalization of home health coverage took place in 1980 when the Health Care Financing Administration (HCFA) began to reimburse for part-time care for as many as 7 days a week and revised reimbursement for skilled nursing and home health aide services up to 35 hours per week (Bishop \& Skawra, 1993). From 1988 to 1996, visits increased by $602 \%$, from 37.7 million to 264.8 million, the number of persons served increased $125 \%$ from 1.6 million to 13.6 million, and the user rate per 1,000 enrollees more than doubled from 40 to 107 (Health Care Financing Administration, 1998). Accordingly, the expenditures for Medicare home health care expanded at a dramatic pace. From 1988 to 1996, payments to home health agencies increased by about $762 \%$, from 1.9 billion to 16.8 billion and in 1996 these payments represented $10 \%$ of all Medicare fee for service payments (Health Care Financing Administration, 1998).

Politics and policies clashed during the 1992 presidential campaign as health care access, costs, and reforms were hotly debated. After the elections of 1992 , home health 
increasingly became a focal point for HCFA now called the Center of Medicare and Medicaid Services (CMS). A home health initiative was formalized in 1993, which found many differences among various agencies, along with regional inconsistencies regarding the numbers of visits per patient for the same diagnosis and cost (Utterback, 2001). The Balanced Budget Act of 1997 (BBA 97) was amended to establish a prospective payment system (PPS) for home health, the fastest growing segment of the health care industry (Payne, Thomas, Fitzpatrick, Abdel-Raham, \& Kayne, 1998). The impetus for the home health PPS was the persistent rapid growth in home health spending from the late 1980s through the mid 1990s.

Under the PPS the home health nurse is responsible for assessing the patient's clinical, functional, and service needs (known as a case mix) according to a standardized data collection tool called the Outcome and Assessment Information Set (OASIS). Based on the data collected using OASIS, the patient is assigned to one of 80 Home Health Resource Groups (HHRGs) for a given episode of care, defined as a 60 day period during which multiple home care visits may be made. The HHRGs range from groups of relatively uncomplicated patients to those containing patients who have severe medical conditions, severe functional limitations, and need extensive therapy. The 80 items are categorized into clinical, functional, environmental, caregiver, and service utilization dimensions, with most accompanied by an ordinal rating scale ranking the patient's status at the time of the assessment (Anderson, Madigan, \& Helms, 2001). Under the PPS reimbursement rates are determined for each HHRG (essentially a resource utilization) so the home health agency knows in advance how much of its costs for a particular patient's care will be offset by Medicare (Utterback, 2001). Since 2001 agencies have submitted 
OASIS data for both Medicare and Medicaid reimbursement. The assumption is that the agencies will provide a higher level of care or more efficient level of care and achieve better patient outcomes if paid on a prospective episode basis rather than on a retrospective fee for service (Sienkiewicz, 2004).

\section{OASIS}

The Outcome and Assessment Information Set (OASIS) is a group of data items developed, tested, and refined over 10 years through an extensive research and demonstration program funded largely by the CMS (HCFA), the Robert Wood Johnson Foundation, and New York State (OASIS, 1998). The OASIS items were designed for the purpose of enabling the rigorous and systematic measurement of patient home health care outcomes, with appropriate adjustment for patient risk factors affecting those outcomes (OASIS, 1998). Outcomes have been defined in many ways, but those derived from OASIS items have a very specific definition: they measure changes in a patient's health status between two or more time points (OASIS, 1998). OASIS provides a common national core standard assessment data set that has evolved into a national home care data set of outcome measures that directly affect consumers' satisfaction with home health care. The rationale behind the OASIS adoption and integration is that through the use of this data set and defined collection intervals, the home care industry has begun to form the foundation for continuous quality improvement (Gingerich \& Ondeck, 1999). Outcome measures are the crux of outcome based quality improvement (OBQI), which is a systematic approach home health agencies implement and follow in order to continuously improve the quality of care they provide. Under OBQI, quality is measured against the ultimate yardstick, patient outcomes (OASIS, 1998). Home health agencies 
are provided with reports on a series of outcomes for their patients in the current year compared to prior year and national reference values. In order to provide meaningful benchmark data the comparisons must adjust for patient risk factor differences (both over time for the agency and between the agency and the reference group) (OASIS, 1998). By selecting target outcomes (meaning outcomes that have shown no improvement or a decline in status) the agency can focus attention and energy on those care behaviors that produce the target outcomes. This review process results in findings, which in turn must be translated into recommendations for changing or reinforcing certain aspects of care provisions. Subsequent outcome reports will indicate how well the care behavior changes have worked, in terms of patient outcomes. The successful use of the OBQI in the agency emerges as a powerful tool to continuously improve quality for the benefit of patients (OASIS, 1998)

\section{Interventions}

\section{Home Care Interventions}

Patients are referred to certified home health agencies by a physician. Patients receiving home health benefits must be homebound and require a skilled intervention. A skilled intervention is defined as an assessment of the patient status, education of the patient or caregiver, performance of care, and administration of a medication (Conditions of Participation, 2002; Mezey \& McGivern, 1999). Patients are either admitted post discharge from the hospital or they experience a precipitating health event that requires skilled intervention by an RN, PT, or ST. The registered nurse makes the initial visit if the precipitating event is related to a change in health status and either a physical therapist or a speech therapist can make the initial visit if the precipitating event has been 
resolved but the patient remains with a functional decline. During the admission visit the RN fills out the OASIS form, the assessment form, and generates a plan of treatment in collaboration with the physician, which may include referrals to other disciplines. RN interventions include assessment and reassessment of patient status throughout the home health stay, performing a procedure such as wound care, administering medications like intravenous antibiotics, and education to the patient and caregiver about their medication's, the disease process, and interventions to prevent exacerbations of a particular disease (Portillo \& Schumacher, 1998; Mezey \& McGivern, 1999). The increasingly The increasingly complex care required by home care patients means that experienced home care nurses are dealing with client situations requiring an unprecedented level of clinical judgment. The isolation from professional colleagues inherent in home care makes clinical decision-making all the more difficult (Conditions of Participation (COP), 2004; Portillo \& Schumacher, 1998).

Patient progress is evaluated at interdisciplinary care conferences, a requirement of the Conditions of Participation, held every two weeks at the home health agency (COP, 2004). At the care conferences the $\mathrm{RN}$ and other disciplines involved in the care give a brief synopsis of the patient's status and bring up any problems that are interfering with the home care regimen. The interdisciplinary team will discuss ways to eliminate the problem or ways to work around the problem to achieve the home health goals. Referrals to other disciplines may be made at this time to help the patient accomplish home health goals (Kane, 1999).

Once the home health goals are met the patient is discharged to the community under the care of the primary physician and the discharge Oasis is completed. Because of 
the increasing complexity of the patients there are times when the patient will be readmitted to the hospital or admitted to a skilled nursing facility. The patient will be discharged without reaching the home health goals and a discharge OASIS will not be completed (Kane, 1999; Mezey \& McGivern, 1999; Portillo \& Schumacher, 1998).

\section{Outcomes}

\section{Effectiveness of home health care}

The definition of effectiveness of home care can be couched in terms of outcomes directly associated with the care, or it can be interpreted in terms of secondary effects, such as displacing or delaying the use of other (presumably more expensive) forms of care (i.e. hospital and nursing home care) (Kane, 1999). A first step in defining effectiveness is goal clarification. Home care addresses two basic contexts for examining outcomes: therapeutic care, more closely associated with home health care, and compensatory care, more closely associated with personal care (Kane, 1999). However, the relationship between therapeutic and compensatory care will vary with the context and intent of the services and these two types of care may coexist. Therapeutic goals usually address maintaining and improving function, but other domains may be equally relevant such as monitoring pain, cognition, social activities and satisfaction with life situations (Kane, 1999). An outcome is defined as the way something turns out, a result, a consequence. An outcome is neither a process, plan of care, assessment, nor a goal (Huffman, 2004). While a patient's outcome is most often defined as a result of care rendered, the CMS definition states that an outcome is a change in patient health status between two or more points in time which may be due to the care provided or the natural progression of illness (Huffman, 2004). Hill (1999) describes outcome based patient 
care as an approach that uses the measurement of patient outcomes as the basis for the provision of patient care. In this context, outcomes, or the result of care rendered, serve as the starting point for improving care. Now that there is a national outcome and assessment information set (OASIS) that can compare various home care outcomes it is important to add to the body of knowledge examining the effectiveness of home care by examining these findings by disease category.

Monitoring the effectiveness of home health nursing care can be traced back to the early decades of the $20^{\text {th }}$ century. Prior to 1950 half of all the deliveries of babies in the United States still occurred at home (Devitt, 1977). Once the pregnancy was confirmed, the "mother to be" usually initiated an employment interview with a prospective nurse. The nurse was the key to promoting medical care for childbirth at the turn of the century because, just as women had felt comfortable in approaching the female midwife in the past, many women contacted the nurse before selecting their physicians (Baer, D'Antonio, Rinker, \& Lynaugh, 2002). Following the delivery of the infant and the placenta, the responsibility for preserving the newly delivered mother's life landed squarely on the nurse's shoulders. In the first hours after delivery the nurse's vigilant watchfulness offered the only security (Baer et al., 2002).

Though this is historical data regarding the effectiveness of home nursing care in relation to maternal health there are many recent studies that show that home nursing remains effective in the public health arena. Koniak-Griffen, Anderson, Verzemnieks, and Brecht (2000) evaluated the effects of an early intervention program (EIP) that uses a public health nursing model on health and social outcomes of adolescent mothers and their children and on the quality of mother-child interaction. Pregnant adolescents 
referred to a county health department were randomly assigned to an experimental (EIP) or control (traditional public health nursing [TPHN]) group. The sample included 121 adolescents from predominantly minority and impoverished backgrounds who were followed in their homes from pregnancy through 6 weeks postpartum. Intense and comprehensive home visitation by public health nurses and preparation-for-motherhood classes were provided to adolescents in the EIP. Early findings indicated reduced premature birth and low-birth-weight (LBW) rates for young mothers receiving both forms of public health nursing care. No significant differences between groups were found for infant birth weight or type of delivery. However, infants in the EIP had significantly fewer total days of birth-related hospitalization and rehospitalization than those in the TPHN group during the first 6 weeks of life. Further, adolescents in the EIP demonstrated significantly more positive educational outcomes (e.g., lower school dropout rates) than those in the TPHN group. The findings of this study demonstrate that pregnant adolescents benefit from both traditional and more intense public health home nursing care in terms of prenatal, perinatal, and maternal outcomes.

Fetrick, Christensen, \& Mitchell (2003) also examined whether public health nurse home visitation made a difference in the health outcomes of pregnant patients and their children. Public health nurses (PHNs) at Lincoln- Lancaster County Health Department have used the Care Pathway tool to track client progress (Lowry \& Beikirch, 1998). Conceptually similar to critical pathways used in hospital settings the Care Pathway is used by the PHN to document milestones of progress by trimester of pregnancy. The researches chose hemoglobin as an indicator of a healthy pregnant mother who ate a balanced diet during the pregnancy and low birth weight to indicate a 
poorer outcome of the pregnancy. Data were collected from chart review of 55 prenatal patients. The study sample was $42 \%$ non-white, $14 \%$ Hispanic, $9 \%$ Asian, $7 \%$ African American, 6\% Native American, and 6\% other. Maternal subjects who had received five to nine home visits by the PHN during pregnancy showed a higher average hemoglobin and their infants had a higher average birth weight compared to babies of mothers visited four or less times. Seventy five percent of the mothers who had more than five home visits had a hemoglobin within normal ranges, and seventy eight percent had infants with a higher average birth weight.

Kearney, York, and Deatrick (2000) studied the effects of home nursing visits on vulnerable young families. Their sample consisted of 20 experimental and quasiexperimental studies of home nursing interventions for families of newborn infants who were vulnerable because of poverty, social risks, or prematurity. This integrative review was designed to allow investigators to answer the following research question: "What are the characteristics of nurse-delivered home visiting programs that have been found effective in improving: (a) maternal health and life-course development; (b) parenting skills and outcomes; (c) maternal-child interaction; (d) child health and development; and (e) use of well-child health care?"

A systematic qualitative evaluation rather than a quantitative meta-analytic approach was used because the diversity of populations and intervention designs could produce misleading or uninterpretable results, if pooled statistically. The sample was delimited to published studies of home-based, nurse-delivered preventive and health promotion care to families with preterm and full-term infants. It included studies in which nurse home visiting was combined with other interventions. Further inclusion criteria 
included: experimental or quasi-experimental design, published in 1970 or later, conducted in the United States or Canada, involved nurses in a nursing-specific role in home visiting, initiated in pregnancy or the newborn period, and reported early childhood outcomes. Combined sample size across 20 studies included 4,538 families and 4,545 infants, with a range of 30 to 1139 families and a median of 105 . Fifteen studies targeted samples with maternal social risks, three were aimed at parents of preterm infants, and two targeted socially at-risk families of preterm infants. Three used nonrandom comparison groups, and the remainder was randomized, controlled trials. Nine programs were initiated in pregnancy and 11 after birth. Duration of home visiting ranged from 3 months to 3 years. Sample retention ranged from $32 \%$ to $100 \%$ and averaged $82 \%$.

Nurse home visiting had a more consistent effect on maternal well-being, interaction, and parenting than on child health or health care use. Effective interventions with families of full-term infants were multifocal, intensive programs lasting 2 or more years, or were of shorter duration (6 months to 1 year) and used graduate-educated nurses who focused on building relationships and enhancing maternal-infant interaction instead of teaching parents in a uniform, directive fashion. The interventions with the longest follow-up indicated the broadest range of positive effects. All five studies of families with preterm infants achieved modest to impressive positive effects. Researchers who compared the cost of their interventions to usual care reported savings. Nurse home visiting generally was less effective when projects designed to alter specific parenting behaviors in families with pre-existing problems, such as drug use, smoking, or observed risk of child abuse. Nurse home visiting improved maternal outcomes and parenting in about half the studies, but less than one-third of studies measuring child development 
outcomes showed positive effects. The skills found important in effective home visiting, including relationship-building and therapeutic use of self and resources to promote family health and child development, are squarely within the province of professional nursing and less likely to be developed in lay community visitors or paraprofessionals.

In nurse-delivered home visiting interventions to young families of preterm and full-term infants, maternal well-being and life course development, maternal-infant interaction, and parenting often improved, but child development gains mainly were limited to preterm infants. Use of well-child health care was not improved by nurse home visiting. Effective nurse home visiting included nurses with advanced education, frequent visits over a long period of time, and were focused less on building parent resources, as in the social ecology model, and more on building a relationship with the mother and providing her with coaching in maternal-infant interaction and cognitive development. Future nurse home visiting research should test a combination of these components and include long-term follow-up of child development. Nurses can advocate for funding of well-prepared nurses to deliver these effective interventions to vulnerable families.

David Olds and associates series of randomized clinical trials of nurse home visitation are often cited as the gold standard for home visitation programs. The NurseFamily Partnership (NFP) Program started over 20 years ago in Elmira, New York serving first-time mothers who were predominately young, unmarried and poor. It subsequently expanded to serve socially disadvantaged families in Memphis, Tennessee (Kitzman, Olds, Henderson, Hanks, et al., 1997; Olds, 2002), and Denver, Colorado (Olds, 2002; Olds, Robinson, O’Brien, Luckey, et al., 2002). The model employs perinatal and early childhood home visitation by nurses as a means of improving parental 
behaviors and environmental conditions early in the life cycle in an effort to prevent a host of maternal and child health problems (Olds, 2002). For the Colorado study, paraprofessionals were included and the effects of home visits by nurses to visits by paraprofessionals were compared (Olds, Robinson, O'Brien, Luckey, et al., 2002). More recently the model is being replicated in high-risk communities in 20 states across the country. Their longitudinal intervention program targets families on the basis of demographic attributed risk factors and has demonstrated consistent effects in several areas of the major outcome domains it has targeted (Reider \& Olds, 2003) including (a) improved maternal like course, specifically fewer or deferred subsequent pregnancies, (b) increased employment rates, and (c) fewer months on welfare (Kitzman et al., 1997; Olds, 2002; Olds, Robinson, O'Brien, et al., 2002; Olds et al., 1997). Program benefits were concerted among selective subgroups and were limited to very long term and not short term effect (Olds, 2002, 2003).

Home health is not limited to maternal child health. Notably, home care provides health and related services for people in their own homes so that they can continue to live independently and avoid admission to acute care or long-term care facilities. Financial constraints related to hospitals and constraints on the growth of long-term and chronic care facilities have led health care planners to look to home care services to provide better integrated care and a lower-cost alternative to hospital and residential care.

Home health care effectiveness has been tested and shown to have positive outcomes in a multitude of studies within the nursing literature. The following studies have been selected to shown the effectiveness in a broad spectrum of home health care. The first group of studies will examine the use of specialized home care interventions. 
Specialized Home Care Interventions

McCorkle, Benoliel, Donaldson, Georgiadou, Moinpour, and Goodell (1989) conducted a randomized clinical trial to assess the effects of home nursing care for patient with progressive lung cancer. One hundred sixty-six patients were assigned to either an oncology home care group (OHC) that received care form oncology home care nurses, a standard home care group (SHC) that received care from regular home care nurses, or office care group (OCG) that received whatever care they needed except for home care. Patients were entered into the study 2 months after diagnosis and followed for six months. Patients were interviewed at 6 weeks intervals across five occasions. The study measured symptom distress, pain, concern as the source of distress, perception of one's own feelings, and health perception.

The investigators found no differences in pain, mood disturbance and concern among the three groups. However, significant differences were found in symptom distress, enforced social dependency, and health perceptions. The two home nursing care groups had less distress and greater independence 6 weeks longer than the office group $(p=0.03)$. Paradoxically, the two home nursing care groups reported worse health perceptions over time $(p<0.05)$. The office care group, which indicated more symptom distress and social dependency over time $(p=0.02)$, also indicated perceptions of improved health with time. The researchers explained their findings by suggesting that the discrepancy between improved health perceptions and increased symptoms and dependency for the OC group could be due to denial or by a denial like process. Another explanation may be that the subjects in the OC group were told they were doing well by 
the physician who may have helped the patients create illusions about the situation (McCorkle, Benoliel, Donaldson, et al., 1989).

Ketelaars and associates (1998) studied the effects of specialized community nursing care in 115 patients with chronic obstructive pulmonary disease using a pretestposttest control group design. Patients were observed for 1 year. The experimental group was visited after discharge by specialized respiratory community nurses from the Heuvelland home care agency. The control group patients were assigned to general community nurses from three other home care agencies. All specialized nurses participating in the study received in-service training in the area of respiratory diseases and treatment: pathology, diagnosis, medication and oxygen administration, rehabilitation regimens, psychosocial problems, and after-care home visiting. Periodic meetings aimed at promoting expertise were regularly held.

During the home visits from general and specialized nurses, no physical examinations were performed. Instead, relevant topics were discussed with the patients, information and advice were given and, if necessary, referrals to other services were made based on individual needs. The home visits varied in number and were as frequent as the nurse and patient considered necessary. In most cases, one or two home visits were made. The number of home visits did not differ significantly between general and specialist nurses (Ketelaars, Abu-Saad, Halfens, Schlosser, Mostert, \& Wouters, 1998).

The study findings revealed that post rehabilitation specialized respiratory nursing care did not demonstrate superior results regarding HRQL, coping behavior, compliance, and hospitalization, when compared with general nursing care in patients with severe 
COPD. However, patients in the experimental group were significantly more satisfied with the care provided by the specialized respiratory nurse.

Limitations to this study include flaws in the study design that may be accountable for the results. The researchers state that it was impossible to blind the nurses to the study, the generalists may have compensated in their care, thus minimizing the potential for improvement. Furthermore, one may question whether the intervention provided by specialized nurses can achieve improved benefits. Because the relationship between process and outcome of care is complicated, and COPD demands treatment for several years, home nursing care might not be able to significantly influence the condition of the COPD patient. One may question whether the intervention, as carried out in this study, is intensive enough to achieve benefits in a group of severely ill patients with COPD. Although specialized home nursing care is an innovative method, a cocktail of different methods for delivering care might be needed to prevent relapse or rehospitalization. These methods might include phone follow-up, group follow-up sessions in the pulmonary rehabilitation center, patient support groups, and follow-up physiotherapy at home

McCorkle, Strumpf, Nuamah, Adler, et al (2000) compared the length of survival of older post-surgical cancer patients who received a specialized home care intervention provided by advanced practice nurses (APNs) with that of patients who received usual follow-up care in an ambulatory setting. The 375 patients recruited into the study were aged 60 or older; diagnosed with a solid tumor in the 2 months immediately preceding primary surgical removal of their cancers; and given a survival prognosis (as determined by the operating surgeons and/or patients' primary physicians) of 6 months or greater 
after the surgery. One hundred ninety patients were randomized to the intervention groups and 185 to the usual care group.

The experimental groups home care intervention was developed as a standardized protocol delivered by APNs that consisted of standard assessment and management guidelines, doses of instructional content, and schedules of contacts. Patients in the intervention group and their family caregivers received comprehensive clinical assessments, monitoring, and teaching over a 4-week period. The intervention was delivered during three home visits and five telephone calls. The APNs followed specific guidelines to assess and monitor the physical, emotional, and functional status of patients, provide direct care when needed, assist in obtaining services or other resources from the community, and provide teaching, counseling, and support during the period of recovery (McCorkle, Strumpf, Nuamah, Adler, et al., 2000).

Despite the randomization, there were differences between the experimental and control groups on stage at diagnosis, with the intervention group having more late stage patients $(38 \%)$ compared with the control group $(26 \%)(p=.01)$. When the two groups were stratified on stage, a significant difference in survival was found between the two groups. Subgroup analysis revealed that among early stage patients, there was no difference between the intervention and control groups. However, among late stage patients, survival time was considerably improved in the intervention group compared with the control group. Eighty-seven percent of the deaths occurred during the first 2 years of follow-up, with 35 deaths in the intervention group and 46 deaths in the control group. Two-year survival rates among early stage patients were $90.3 \%$ in the intervention 
group and $87.6 \%$ in the control group. However, in the late stage patients, 2-year survival rates were $66.7 \%$ in the intervention group compared with $39.6 \%$ in the control group $(p<.05)$ (McCorkle, Strumpf, Nuamah, Adler, et al., 2000)

The generalizability of these findings is limited to newly diagnosed older patients with selected solid cancers. The sample included only older patients who were admitted to an urban academic health center and who were treated with primary surgical removal of their cancers. Patients came from home and were alert and oriented at admission. In general, the patients were well educated and had good support systems; most had minimal functional deficits before surgery. Replication with older cancer patients from various settings, from other geographic areas, and under various socioeconomic conditions is warranted.

The efficacy of a home based nursing program in Taiwan for diabetic control of elderly patients living alone was examined by Huang, Wu, Jeng, and Lin (2004). Using convenience sampling 44 subjects agreed to participate in the study. By matching the effects of age ( \pm 2 years), sex, education, and history of diabetes, subjects were assigned to the "home-based nursing program" (Group $I, n=15$ ) or the "education program" (Group II, $\mathrm{n}=15$ ). Patients who agreed to only receive the blood examination were assigned to the control group $(n=14)$. All subjects were aware that they had entered into the study.

In the first experimental group (Group I), participants received "home-based nursing Program I" for 6 weeks. Program I consisted of daily visits by nursing to supervise subjects' diet preparation, exercise performance, medication, and selfmonitoring of blood sugars. . The second experimental group (Group II) participants 
received "nursing Program II," which provided health education information and selfmonitoring of blood sugar, also for 6 weeks. The educational material was based on a booklet, "Health Education For Diabetes Mellitus Patients About Diet, Exercise, Medicine and Self-monitoring Of Blood Sugar," compiled by the investigators. The educational material was presented to Group II subjects during 20-30-min sessions held once per week. During the 6-week program, post meal blood sugar was checked every week. For the control group, no specific nursing program was provided, but blood sugar and lipids were checked prior to and after the 6-week program of Groups I and II.

This study found that the mean differences of fasting blood sugar, post meal blood sugar, and $\mathrm{HbAlc}$ of the three groups were statistically significant with groups I \& II having lower blood sugars and $\mathrm{HbAlc}(\mathrm{p}=0.01)$. The mean differences of HDL and TG between the groups were not statistically significant. The average pre- and post program HDL values increased $(1.20 \mathrm{mg} / \mathrm{dl})$ in Group I but decreased in Group II and the control group. The mean differences of TG decreased much more in Group I than in Group II and increased in the control group. This indicates that "home-based nursing Program I" improved HDL and TG. For body weight, the mean difference of Group I was much higher than that of Group II ( $p<0.001)$, indicating that Program I is better than Program II. For level of depression, the mean differences between Groups I and II were not statistically significant; however, the decrease was less in Group II than Group I. The mean differences for the quality of life scores between Groups I and II were not statistically significant, which might be due to the small sample size (Huang et al., 2004).

Because of sample size limitations, some variables were not significant; however, most biochemical data such as fasting sugar, post meal sugar, HbAlc, cholesterol, and 
LDL were significant. Results demonstrate that a "home-based nursing program" can improve glycemic control of elderly diabetics living alone. This can be extended to the public health nursing arena as a means to improve current care programs for elderly diabetics living alone.

In another study exploring the role of a single home based intervention, patients in the treatment group were paid a single home visit one week after discharge by a nurse and a pharmacist to optimize medication management, identify early clinical deterioration and intensify medical follow up and caregiver vigilance. The study had two groups of patients, 142 patients in the home care intervention study and 140 in the conventional care interventions group, mean age 70 yrs of age. Survival for 90 days without readmission was achieved in 91 of the 142 patients in the treatment group, as compared with 75 of the 140 patients in the control group. There were 94 readmissions in the control group and 52 in the treatment group (risk ratio, $0.56 ; p=0.02$ ). This single visit resulted in a significant reduction in unplanned readmissions, total hospital stay, hospital based costs and mortality. These changes were sustained for at least 18 months after the home based interventions (Rich, Beckham, Wittenberg, Leven, Freedland, \& Carney, 1995).

A large study was conducted in a large urban non-profit home health agency during 1996 to examine an intervention design that standardized nursing care, strengthened support for individual self management and yield better outcomes for congestive heart failure (CHF) patients (Feldman et al., 2004). The interventions consisted of: (1) a formal nursing protocol or "Health Outcomes, Management and Evaluation (HOME) Plan, (2) a consumer oriented patient self care guide, and (3) 
interactive practitioner training designed to improve nurse's patient teaching and support skills. The HOME Plan and the patient self-care guide were adapted from the heart failure guideline developed by the Agency for Healthcare Research and Quality in 1994 The HOME Plan identified steps the nurse coordinator of care should take to help the patient achieve proper and timely administration of prescribed medications, adhere to dietary and activity recommendations, record accurate and consistent daily weights, and recognize signs and symptoms requiring immediate contact with a physician. It outlined 12 specific objectives to be achieved by the nurse within nine visits, over a four-week episode of home health care. The patient self-guide was published in both Spanish and English with illustrations and language accessible to someone with a sixth grade education.

The study randomized nurses to an intervention or control group and compared service use and outcomes for patients served by nurses in the respective groups. Three hundred and seventy one patients with $\mathrm{CHF}$ as their primary home health diagnosis were included in the study, subjects were 65 or older (with average age 81 years old) spoke English or Spanish, and provided written informed consent to participate in the study. The dependent variables were ER use, MD visits, hospital admissions, quality of life, satisfaction with home care, and number of home care visits made by nurses (Feldman et al., 2004).

The study found that patients served by intervention nurses had lower visit variance compared to those served by control nurses. The predicted number of skilled nursing visits for intervention patients was 16.1 compared to 19.6 for control patients. A test of the null hypothesis that the variance was equal verified that this difference was 
statistically significant $(\mathrm{F}=1.48 ; p<0.05)$. There was no difference in the number of visits to the physician between the intervention group and the control group within 90 days of admission to home health. In other words, the decrease in home health visits for the intervention patients did not result in more physician visits. Significant predictors of a higher volume of physician visits during the follow up period were a higher volume of physician visits prior to admission and admission to home care from the hospital. There was no difference between intervention groups and control groups in number of ED visits during the 90 days after admission to home health. Variables that predicted ED use were use of ED within the 90 days prior to admission to home care; the number of self reported comorbid conditions and the median income of the zip code are where the individual lived. Overall, 64 patients (35\%) served by the control nurses and $68(36 \%)$ served by intervention nurses were admitted to a hospital within 90 days, following their initial admission to home care. The unadjusted mean number of days of hospitalization for all patients served by control and interventions group nurses in the 90-day follow up period was 5.2 and 5.8 days respectively. The study found that intervention did not have a significant effect on quality of life as measured by the LHFQ and no difference between the intervention group and control group in patient satisfaction (Feldman et al., 2004).

The intervention was not a success as outlined by the designers of the HOME Plan. Home health nursing visits were decreased but none of the other goals were achieved. The intervention did not have a negative effect on the patients. It was noted in the study that the predictors of ED use and hospitalization were patterns of prior use of these services. Quality of life scores were driven by dependencies on activities of daily living (ADLs) and instrumental activities of daily living (IADLs) at baseline. Patient's 
satisfactions were related to marital status, baseline cognitive status, functioning and baseline functioning. The study yielded no evidence that nursing intervention in training in the use of patient care guide or inpatient education affected patient's perception of their provider's responsiveness, clinical skill, efficiency or communication (Feldman et al., 2004).

In summary, these 6 studies looked at the effectiveness of home care in the general population utilizing specialized home care interventions by nursing. Several investigating teams (Ketelaars et al., 1998; McCorkle et al.,1989, 2000) examined specialized home care with usual home care for a specific disease group. McCorkle and associates $(1989,2000)$ also compared specialized home care, usual home care with office and clinic care. Each found that the quality of life improved with both specialized home care and usual home care verses office care or clinic care. McCorkle and associates (2000) noted that specialized home care found that patients in the intervention group lived longer and also had a quality of life comparable to the usual care group who had more early stages of cancer. Ketelaars et al.(1998) found that patients were more satisfied with specialized home care verses usual home care. Huang et al. (2004) found that specialized home care interventions improved diabetic management in the elderly. Rich et al. (1995) found that just one visit by a home nurse and pharmacist improved patient outcomes. Only Feldman and associates (1996) study indicated that specialized interventions versus usual care did not improve outcomes.

Intrator and Berg (1998) examined the benefit of home health services for elderly patients with hip fracture discharged home after inpatient rehabilitation. Their study population consisted of patients hospitalized with a hip fracture, 70 years or older, who 
had no major Medicare claims during the year before hospitalization and who were discharged home after inpatient rehabilitation. They found that patients who received additional home health services were less likely to be hospitalized (27.2\%) than those who received rehabilitation only (31.1\%). They were also less likely to have a non-SNF nursing home admission (11.3\% vs. $23.3 \%$ ), and more likely to survive the year with no subsequent Medicare claims (65.6\% vs. 55\%). This study found that home health care was associated with a significantly lower risk of nursing home admission (adjusted odds ratio $=.42,95 \%$ confidence interval $.21-.84$ ), and hospitalization (adjusted odds ratio $=$ $.65,95 \%$ confidence interval $.26-1.00)$. Studies of the relative effectiveness of post-acute services and post-discharge evaluations of inpatient rehabilitation should consider additional home care as a post-acute service and examine optimal post-acute treatment to minimize additional service use.

Inglis and colleagues (2004) examined the effects of a nurse-led, multidisciplinary, home-based intervention (HBI) on the pattern of recurrent hospitalization and mortality in patients with chronic atrial fibrillation (AF) in the presence and absence of chronic heart failure (HF). Health outcomes in a total of 152 hospitalized patients ( $53 \%$ male) with a mean age of $73 \pm 9$ years and a diagnosis of chronic AF who were randomly allocated to either HBI $(n=68)$ or usual post discharge care (UC: $n=84)$ were examined. Specifically, the pattern of unplanned hospitalization and all-cause mortality during 5-year follow-up were compared on the basis of the presence $(n=87)$ and absence $(n=65)$ of HF at baseline. In this study patients assigned to HBI $(n=68)$, while receiving the same level of care as those assigned to "usual care," received a structured home visit within a target period of 7 to 14 days post discharge. The 
fundamental aim of HBI was to optimize the management of the patient's chronic disease state(s) and to facilitate the rapid recognition and treatment of potential problems. As such, in this patient cohort, HBI focused on the following: 1) establishing a comprehensive clinical and socio-demographic profile of the patient to determine the factors that were likely to increase or decrease the probability of future events; 2) optimizing patient access to effective multidisciplinary management (involving their primary care physician, specialist physician, community pharmacist, community nurse, and other allied health professionals where appropriate) with clear treatment and outcome goals; and 3) ensuring that the principals of the quality use of medicines, in respect to prescribing, patient management (optimal adherence rates), and minimizing harm were applied. Patient/family education in respect to the management and prognostic importance of $\mathrm{HF}$ and $\mathrm{AF}$ where appropriate, early detection and management of potentially fatal clinical deterioration, facilitating patient-initiated contact to address issues of concern and applying guidelines for the best practice management of $\mathrm{HF}, \mathrm{AF}$, and other chronic conditions where appropriate.

Initial assessment included a physical examination, a review of the patient's adherence to, and knowledge of, prescribed treatment and their medications and their social support system in addition to identification of any other factors likely to increase the probability of readmission or death. Particular attention was paid to those patients prescribed potentially "toxic" pharmacological agents including digoxin and warfarin with increased educational and practical support: primarily through their community pharmacist who ensured that plasma digoxin and International normalized ratio (INR) levels were monitored and the dose of drug adjusted accordingly (Inglis et al., 2004). 
Patients with concurrent HF exposed to HBI $(n=37)$ had fewer readmissions $(2.9$ vs 3.4 patient), days of associated hospital stay (22.7 vs 30.5$)$ and fatal events (51\% vs $66 \%)$ relative to $\mathrm{UC}(\mathrm{n}=50)$ : for all comparisons. In the absence of $\mathrm{HF}$, morbidity and mortality rates were significantly lower but still substantial during 5-year follow-up. In these patients, $\mathrm{HBI}$ was associated with a trend towards prolonged event-free survival (adjusted $\mathrm{RR}=0.70 ; \mathrm{p}=.12)$ and fewer fatal events $(29 \%$ vs $53 \%$, adjusted $\mathrm{RR}=0.49 ; \mathrm{p}$ $=.08)$. HBI patients $(n=31)$ also had fewer readmissions $(2.1$ vs $2.6 /$ patient $)$ and days of associated hospital stay (16.3 vs 20.3 /patient), although this did not reach statistical significance (Inglis et al., 2004).

Li, Morrow-Howell, and Procter (2004) examined the hospital readmission of elderly patients with congestive heart failure. The purpose of this study was to examine the independent and joint effects of informal and formal service use on hospital readmission. The study examined 240 patients that were 65 years of age or older, diagnosed with CHF, discharged to a home setting, and served by a discharge planner. The dependent variable was hospital readmission, the major independent variables were informal service use, formal service use, and joint use of informal and formal services. Informal service use was defined as the use of nursing care, ADL assistance, and IADL assistance provided by unpaid helpers. Formal service use was defined as the use of nursing care, ADL assistance, and IADL assistance provided by paid helpers. ADLs or IADLs refer to the activities elderly people need to perform while living in the community independently. Nursing care focused on checking blood pressure and soundings of heart and lungs, drawing blood, giving injections, and providing catheter care. 
Findings indicated that these models significantly predicted hospital readmission. However, there was no evidence to suggest that informal service use, formal service use, or joint use of informal and formal service reduced hospital readmission. Several factors may have contributed to the insignificant findings. First, the theoretical link between service use and outcomes has not been well understood (Hawes \& Kane, 1991). Although researchers have proposed that use of health services may improve patient's health and well-being (Andersen, 1995), they often fail to specify or rationalize the relationship. In the study of home health services, investigators rarely justify the relationship between the services provided and the outcome anticipated, thus they often do not know whether use of home health services is directly related to service outcomes, such as improvement in functioning or well-being, or through other intermediate outcomes, such as meeting dependency or medical care needs. It is important to examine how intermediate outcomes may affect service outcomes in future studies. Second, this study was a secondary data analysis, and the investigators were limited to the variables that were already collected. For example, the joint use of services independent variable was created to reflect the conceptualization proposed in task-specific theory. This categorical variable may not capture the complexity of how informal and formal services were integrated. Another independent variable, use of informal or formal services, was measured by number of service episodes per week. This measure provided no information on the quality of services or whether services met the needs of elderly patients. Moreover, informal and formal services in the study focused on nursing care, ADLs assistance, and IADLs assistance and did not include services provided by physicians and other professionals, which could have resulted in an underestimation of formal service use. In addition, the 
dependent variable was defined as any hospital readmission. The investigators did not know whether the readmission was due to CHF or to other unrelated conditions. Third, the variations in the service delivery process may trivialize the effects of informal and formal services on hospital readmission. Post-acute home health care service providers vary from highly trained professionals to paraprofessionals to informal caregivers. Meanwhile, service delivery and quality may vary from agency to agency. It is challenging to control these variations in a study with a relatively small sample size (Hawes \& Kane, 1991). Given the available data, investigators were only able to separate informal and formal services and identify and control some other confounding factors in the models, which were not adequate to minimize the threats to internal validity. Fourth, the measure used to correct collinearity may have minimized the effects of informal services on hospital readmission. Consistent with other studies, findings from this study show that functional status of elderly people is highly correlated with levels of informal services. It is understandable that informal service provision is dependent on the functional needs of elderly people (Kane \& Kane, 1987). Residual informal service use, a part of informal service use that is not correlated with functional status, may not be able to produce the same effect on hospital readmission as informal service use does. Fifth, the study participants were recruited from a large, urban teaching hospital, which may limit the generalizability of the study. Lastly, data were collected between 1989 and 1991 and certain issues during this period may or may not be relevant to current health care.

In 1999, Stewart, Morley, and Horowitz, conducted a large study to examine the effects of home care on patients with chronic congestive heart failure (CHF). The sample population consisted of $200 \mathrm{CHF}$ patients, with a mean age 71 years and a majority of 
males $(62 \%)$. One hundred patients were assigned to the usual multidisciplinary team, which included a physician, outpatient clinic, and cardiac rehabilitation. The other 100 patients were given the same treatment as the first 100 with the addition of one home health visit by a cardiac home health nurse within 7-14 days post discharge. During this visit the nurse did a physical, and assessed patient's adherence to diet, treatment, understanding disease process, fluid and sodium intake, physical activity, and community based support. At 6 months the 100 patients who had the addition of the home health nurse had fewer health events (unplanned admissions or death) (77 versus 129), less unplanned admissions (460 versus 1174). The groups did not differ on out of hospital deaths.

Stewart, Vanderbrock, Pearson, and Horowitz (1999) extended the study to include a follow up at 18 months. During the 18 month follow up, the HBI patients had fewer unplanned readmissions (64 vs $125 ; \mathrm{p}=.02)$ and out of hospital death ( 2 vs $9 ; \mathrm{p}=$. $02)$, representing 1.4 vs 2.7 events per HBI and usual care patient, respectively $(p=.03)$. The HBI patients also had fewer days of hospitalization $(2.5 \mathrm{vs} 4.5 ; \mathrm{p}=.004)$ and once readmitted, were less likely to experience 4 or mote readmissions ( 3 vs $12 ; p=.03$ ).

The common theme in the preceding 5 studies is the outcome for decreased hospitalization and or decrease in health events. Li et al. (2004) found that there is no significant decrease in hospital admission between patients who use formal or informal home care. The other four studies indicated that home care interventions do have an affect on decreasing the admission rate of patients with chronic diseases (Inglis et al., 2004; Intrator \& Berg, 1998; Stewart, Morley, \& Horowitz, 1999; Stewart, Vanderbrock, Pearson, \& Horowitz, 1999). 
In the study reported here usual care in home care and its effect on functional status was examined. Although prior studies have examined usual care, and overall home heath care has been found to be effective in reducing hospital admissions (Stewart et al., 1999) further studies are needed to examine the effect of home health interventions on specific outcomes such as functional status.

\section{OASIS for Measurements}

Five studies, searching CINAHL and MEDLINE, were found utilizing OASIS as a measurement for the effectiveness of home care. Berquist (2003) used OASIS data to determine whether admission data routinely collected on the Outcome and Assessment Information Set might be predictive of pressure ulcer development in patients receiving home health care. The study was a secondary analysis of data from a retrospective cohort study of risk factors for pressure ulcer development in older adults conducted in a large mid western urban home health care agency. The medical records of 1820 non-hospice, non-intravenous therapy patients were reviewed for the presence of a pressure ulcer. Patients were 60 years and older and were admitted to the intermittent skilled nursing division of the home health care agency between January 1995 and March 1996. Of the 1070 patients $62.5 \%$ were women. Common medical conditions included heart disease, hypertension, musculoskeletal and connective tissue disease, diabetes, COPD, and cognitive disorders. Only the first admission was considered for patients admitted more than once during the study period. Patients admitted with a stage 1-1V were excluded from the study. The 1711 patients who were free of pressure ulcers on admission were included in the cohort sample. The independent variables were gender, type of medical condition, medications, residence, caregiver, level of activity, use of oxygen, pain, 
dyspnea, urinary incontinence, bowel incontinence, Foley catheter, depression, anxiety, confusion, unresponsiveness, short/long-term memory deficit, lack of concentration, impaired reasoning, and level of IADL and ADL. These are all questions asked and answered on the OASIS document upon admission to home care. The dependent variable was the development of a pressure ulcer and the staging of the pressure ulcer.

Patient's records were followed prospectively to 1 of 2 outcomes; pressure ulcer development or no pressure ulcer development. Data analysis was conducted using the SPSS 11.0. Descriptive data were analyzed and differences between subjects with and without pressure ulcers were tested using independent sample $t$ tests. Bivariate associations between each OASIS like variable and pressure ulcer were examined using simple Cox proportional hazards regression procedures. Multivariate analyses of factors significantly associated with pressure ulcer development in bivariate analysis were conducted using forward stepwise Cox regression procedures. A significance level of .001 or less was used to account for the number of variables involved in the multivariate comparisons (Berquist, 2003).

Following admission to home health 53 subjects developed a Stage I pressure ulcer, 54 subjects developed a Stage II pressure ulcer and one patient developed a Stage III pressure ulcer. No one developed a stage 4 ulcer. There were no statistically significant differences between subjects who developed a stage 1 pressure ulcer and subjects who developed a stage 11 or higher ulcer with respect to age, gender, number of medical diagnosis, time to pressure ulcer discovery, and number of nursing visits. The study found that limitations in activity while in bed, dependence in dressing, urinary incontinence, needing assistance with transferring predicted a stage one pressure ulcer. 
Predictors for Stage II pressure ulcer were bowel and bladder incontinence, oxygen use, a current fracture, and dependence in dressing ( $\mathrm{r} \geq 0.3, p \leq 0.01)$ (Berquist, 2003).

The findings in this study are consistent with the literature that indicates that impaired mobility, limitations in activity, moisture, and friction predispose to developing pressure ulcers in hospital and nursing home patients. Therefore the admission OASIS assessment may provide a method for identifying elderly patients who are at risk for developing a Stage 1 and/or Stage II pressure ulcers in home health care.

Keepnews, Capitman, and Rosati (2004) examined the use of the Outcomes Assessment and Information Set (OASIS) data to analyze patient level outcomes of home health care. OASIS data was obtained on 1015 patients who received home health care services for 60 days or fewer from a large, independent home health agency between August 1998 and December 1999. Using least squares regression with backward deletion they analyzed outcome of home health care based on an index constructed from the patient's scores on 16 OASIS measures of functional abilities. Of the 16 OASIS measurements 15 were ADL and IADL measurements and one additional measure for frequency of pain interfering with functioning. Data for each of these measures were collected by the clinician and recorded on the OASIS instrument. The study found $78.1 \%$ of patients improved, $18.4 \%$ declined and $2.8 \%$ showed no change. Of a maximum possible score of 1600 on the functional status index patients had a mean score of $1068.65(\mathrm{SD}=297.85)$ on admission $(66.8 \%$ of the maximum possible score $)$ and a mean score of $1253.05(\mathrm{SD}=301.58)$ on discharge (78.3\% of maximum possible score).

Dalton (2001) conducted a case study utilizing OASIS data in evaluating a cardiac disease management program, to identify the problems encountered and the knowledge 
gained. A sample of 51 patients was selected from the population of approximately 100 cardiac patients who were admitted to the Cardiac Disease Management Home Care Program between November 1997 and December 1998. The 51 patients had completed admission and discharge data. The clients ranged in age from 45-98 years $(M=71.4)$. Twenty-three (45.1\%) were male and $28(54.9 \%)$ were female. The study examined the number of patients in each score category and comparison of patient outcome OASIS scores at admission and discharge. Only patients who were discharged to the community were included in the comparison of admission and discharge scores $(n=40)$. All 51 patients were included in the analysis of the admission data. The specific functional outcomes that were measured on admission and at discharge included the patient's ambulation/locomotion ability, transferring ability, bathing ability, ability to prepare and take all prescribed oral medications, level of pain, level of shortness of breath, and level of anxiety. OASIS patient outcome data scales were on an ordinal level of measurement therefore frequency counts and percentage were used to analyze the data. Improvement in the level of functioning was reflected in all of the patient outcomes. The greatest patient outcome improvement was demonstrated in shortness of breath, in which there was a $40 \%$ increase in patients who denied shortness of breath at discharge.

Bowles and Cater (2003) compared the efficacy of the routinely collected OASIS with the Probability of Readmission (PRA) scale in screening patients for risk of hospital readmission during home care. One hundred and forty seven patients were recruited from a large urban home health agency in the Northeast. The patients were 65 or older, had a primary or co existing diagnosis of $\mathrm{CHF}$, were able to see and hear and answer questions, had a telephone, and were insured by Medicare. All eligible patients were assessed using 
the OASIS as is the usual practice in home care and they were also screened using the PRA instrument. The sample was 70\% female, 42\% African American, $21 \%$ Caucasian, and $1 \%$ Hispanic. Twenty nine percent of the patients were re-hospitalized within 60 days of home care admission.

The PRA is an eight item questionnaire used in research and clinical practice to assess factors shown to predict re-hospitalization more than once within 4 years. The patient answers eight questions on demographics, health, social support, and service utilization and is scored according to a logistic equation. The resulting PRA score was a value between 0 and 1 , with higher values indicating higher probability of readmission.

The OASIS was used to assess patient status in three domains. The domain scores also generate a case mix weight set by CMS that ranges from 0.5265 to 2.8113 , with higher scores associated with poorer clinical functional and service scores. Each of the domain scores and the case mix weight were used in this study as a predictor variable for re-hospitalization (Bowles \& Carter, 2003).

The PRA instrument was found to be significantly better at predicting rehospitalization than the OASIS case mix weight, clinical, or service scores. The area under the curve for the PRA was .686 compared with the .549 for the OASIS case mix weight $(p=.010)$. Similar results were found for the OASIS clinical and service scores, therefore it is argued that the OASIS function score could be used to identify at risk home care patients without having to do the PRA (Bowles \& Carter, 2003).

Nelson (2004) compared two different data collection systems (Omaha System and OASIS) and implementation of care of wounds, within the Kenosha Visiting Nurse Association, an independent, non-profit home health agency. A retrospective chart 
review of 30 patients with surgical wounds was conducted. The study was developed to evaluate three primary areas: overall patient care, the consistency in OASIS data responses at the start of care and discharge, and the status of the wound measurement by OASIS data and Omaha System, knowledge, behavior and status ratings at the start of care and discharge. The results of the initial chart audit demonstrated consistent improvement of the surgical wounds status when OASIS data were compared to Omaha System problem rating scores. The average admission knowledge ratings improved from 2.96 to 4.11 at discharge, behavior ratings improved from 4.03 to 4.70 , and status ratings improved from 3.52 to 4.33 . The OASIS document with its valid and reliable standardized definitions provides more precise assessment and follow-up of wound care.

Prior to 2000 there were no national standards with which to study the effectiveness of home care. Each home health agency would decide what was relevant to study for quality of care and the results were kept in the department and not published. The mandatory use of the OASIS tool now gives the home health field a national measurement tool with which to study the outcomes to home health care. Only five studies were found in the literature that used OASIS as an instrument to look at any aspect of home health care. Of these few studies only two have looked at the effectiveness of home care which indicates that there is a real need to add to this body of knowledge regarding home care effectiveness utilizing the OASIS instrument.

Of the OASIS studies conducted to date, Dalton (2001) is the only one to examine cardiac patients; however her sample of 51 was small. Although the outcomes from this study show an improvement in functional status, additional studies need to be conducted 
to contribute to the empirical body of knowledge of effectiveness of home care in patients with a diagnosis of cardiac disease.

\section{Limitations to use of OASIS}

Potential limitations to the use of the OASIS tool include the accuracy of the data collected. In general, OASIS accuracy assumes a "correct answer" for each OASIS item, that given sufficient time, education or some other quality, an individual staff member can obtain good accuracy. Regardless of approach, there are several factors that can influence the accuracy of reliability during collection of OASIS data. First and most obvious, is the expertise of the raters. Expertise includes more than just the number of OASIS assessments done but also how the OASIS is used in the clinical process. For example, does the clinician use the OASIS as part of the process of care or is it an additional piece of documentation that may or may not agree with the other parts of the clinical record (Madigan, Tullai-McGuinness, \& Fortinsky, 2002). The second factor is drift wherein an individual systematically errs in rating specific items, higher or lower) based on inaccurate interpretation of the items. The third factor is concerned with clinical judgment. For any item that is not precisely measured (i.e. tape measure or scale) or is open to perceptual appraisal, two raters rating the same patient at the same time on the same item could legitimately disagree. This may result from imprecision in wording of the item, ambiguity of the response items where a patient could be rated in either category, or level of the assessor's clinical expertise (Madigan, Tullai-McGuinness, \& Fortinsky, 2002). The fourth factor that influences accuracy in ratings is the potential of disciplinary differences, particularly between registered nurses and physical therapists. Physical Therapists tend to be more accurate with functional status items such as 
activities of daily living and instrumental activities of daily living due to their training, but they are less accurate with other clinical items. Finally the method of data collection is critical in obtaining accurate information. OASIS was designed to be incorporated into the overall assessment of the patient not as an addition or a stand-alone measure. Newer nurses and therapists use OASIS as an interview guide and ask the patient or family member each question whereas experienced home health nurses and physical therapists evaluate OASIS items through observation of performances as much as possible (Madigan, Tullai-McGuinness, \& Fortinsky, 2002). Using OASIS solely as an interview, without incorporating observation and clinical judgment, can lead to a patient being scored as more functionally able than an objective observer would rate them.

Gerontology literature identify that many older adults over estimate their functional ability (Santos-Eggiman, Zobel, \& Berod, 1999).

\section{Client}

\section{Cardiac Patients and Functional Status}

The study reported here examined through secondary data analysis whether the functional status of Cardiac patients improved with home care. Patients with a cardiac history comprise $10 \%$ of all home care patients and coronary heart disease $(\mathrm{CHD})$ is the leading cause of death in adults in the United States. An estimated 13.7 million people have coronary heart disease, one half of whom has had an acute myocardial infarction and half have angina pectoris. According to the American Heart Association (2004), about every 29 seconds someone in the US suffers from a CHD-related event, and about every minute someone dies from such event. The lifetime risk of having coronary heart disease after age 40 is $49 \%$ for men and $32 \%$ for women. As women get older, the risk 
increases almost to that of men. One million new or recurrent coronary events were expected in the Unites States in the year 2000 and now the American Heart Association states that 1.5 million persons will have a new or recurrent event in the year 2004 (American Heart Association, 2004; Blanchard, Rodgers, \& Daub, 2002). Healthcare costs related to this $\mathrm{CHD}$ are enormous and account for expenditures that are expected to reach $\$ 329.2$ billion in the near future (Green, Grant, Hill, Brizzolara, \& Belmont, 2003). The mean age of patients with myocardial infarctions in the coronary care unit is now older than 65 years, and more than one third of cardiac operations in adults in the United States are performed in patients older than 65 (Ades, Waldmann, McCann, \& Weaver, 1992). The clinical manifestations of coronary heart disease in older patients represent the effects of the disease superimposed on the physiological effects of age. The presence of obstructive coronary artery disease at autopsy approaches $50 \%$ in elderly women and $70 \%$ to $80 \%$ in elderly men. Although octogenarians comprise $5 \%$ of the US population, they represent $20 \%$ of all hospitalizations for myocardial infarction (MI) and $30 \%$ of all myocardial infarction related hospital deaths. At coronary arteriography, elderly individuals have more extensive coronary artery disease, more multi-vessel disease, more coronary artery calcification, and are more likely to have had a prior MI than patients whose age is less than 65 (Williams et al., 2002).

Congestive heart failure (a consequence of $\mathrm{CAD}$ ) is disturbingly common. It affects approximately 4.8 million people in the U.S. and becomes more prevalent with advancing age. The well-known Framingham heart study found that an average of $3.7 / 1000$ men and 2.5/1000 women are diagnosed yearly with heart failure. This means that over 400,000 new cases of heart failure are diagnosed each year in the U.S. 
Americans spend over 17 billion dollars annually on treatments for CHF (American Heart Association, 2004).

Normal aging changes and health problems, such as CHD, frequently show themselves as declines in the functional status of older adults. One of the best ways to evaluate the health status of older adults is through functional assessment, which provides objective data that may indicate future or present decline or improvement in health status (Shelkey \& Wallace, 1998). Functional status is a key element of healthcare practice and must be incorporated as outcome criteria. As defined by Leidy (1994), functional status is a multidimensional concept that characterizes a person's ability to provide for the necessities of life, that is, those activities people do in the normal course of their lives to meet basic needs, fulfill usual roles, and maintain health and well being. One aspect of functional status is functional performance, which includes activities of daily living (ADLs) such as bathing, dressing, toileting, eating, and instrumental activities of daily living (IADLs) which include housekeeping, telephone use, compliance with medications, self care, and self care activities. Treatment for all home health patients has the goal of returning patients to, or maintaining them at, their highest possible level of self-care and independent functioning. Whether patients are convalescing from an acute illness or suffering chronic impairment, home health treatment is aimed at allowing them to return to or remain at home, and to leave and receive treatment outside of an institutional setting. Functional health status was selected as CMS's outcome measure of choice because it was the greatest interest to Medicare beneficiaries and it reflects the agency's strategic objective of being patient centered. There was evidence that complex issues such as chronic illness, co-morbidity, and functional impairment are particular 
problems among the elderly and present distinct challenges to this population. It was believed that a functional status measure was an important outcome of care, due to the complexities involved in the health of older adults, and because of the growing concern about how managed care would affect these conditions and this population's subsequent functional status (Bierman, Lawrence, Haffer, \& Clancy, 2001). Thus measures of overall functional ability and independence are important ways to assess the efficacy of home health treatment (Keepnews, Capitman, \& Rosati, 2004).

Few studies were found in the literature review that discussed the relationship between functional status and cardiac disease. Wang, Van Belle, Kukull, and Larson (2002) examined 1,873 patients with CAD and found that functional independence is an important component of quality of life. Patients self reported scores on ADL and IADL tests and patients with higher scores (meaning higher functional status) had lower age related rates of functional decline over 4 years of follow up after controlling for baseline function which translated into higher scores for quality of life.

Mithal, Mann, and Granger (2001) studied the role of Coronary Heart Disease (CHD) in functional limitation in community dwelling elders. A group of 33 frail elders with $\mathrm{CHD}$ were interviewed over a period of 6 months using the Lifeware Cardiac Assessment Form. The results of the correlation analysis demonstrated a mild to moderate relationship between the symptoms experienced by the elders and their performance of day to day physical activity.

Redeker and Brassard (1996) examined the health patterns of cardiac surgical patients in the home health care population and their relationships to outcome and duration of home health care using Gordon's Functional Health Pattern framework. The 
categories of functional health patterns are health perception/health management, nutrition/metabolic, elimination, activity/exercise, cognitive/perceptual, sleep/rest, selfperception/self-concept, roles/relationships, sexuality/reproductive, coping/stress, and values/beliefs. They specifically examined the functional and dysfunctional health patterns of cardiac surgical clients admitted to the home health care nursing service and the relationship among age, gender, health patterns, outcomes, and duration of home health care services used by cardiac surgery clients.

Ninety-six consecutive health records were reviewed on clients who had at least one home care nursing visit after coronary artery bypass or valve surgery during 1992 . Forty-eight $(50 \%)$ were women. The mean age of the sample was 71.37 years $(\mathrm{SD}=$ 7.18 , range $=45-84$ ). The health history and assessment forms used in this agency were organized according to the Functional Health Pattern framework All the clients received the services of a home health care nurse. Collaborative services included home health aides, registered dietitians, physical therapists, social workers, occupational therapists, and speech therapists. The mean duration of home health care services was 28.80 days $(\mathrm{SD}=18.02$, range $=1-76)$. Outcomes included discharge from the home care service with goals met, lack of need for skilled services, and readmission to the hospital. The most common reason for readmission to hospital was pulmonary congestion and shortness of breath. The clients' chief complaint on admission to home health care were tiredness, weakness, fatigue, pain, poor incisional wound healing, and dyspnea (Redeker and Brassard (1996).

All of the clients were homebound at the time of the initial visit. Most (98\%) were able to ambulate within their homes. Exercise tolerance, range of motion, and body 
strength were recorded as good, fair, or poor, consistent with the nursing records. Eight Clients $(83 \%)$ had fair or poor exercise tolerance, 40 clients $(42 \%)$ had fair or poor range of motion, $38(40 \%)$ had fair to poor upper body strength, and $57(59 \%)$ had fair or poor lower body strength. Fifty percent of the clients attributed this to weakness, shortness of breath and dyspnea. The majority of clients $(77 \%)$ had correct medications at their homes and were able to identify their medications correctly; however $50 \%$ of the clients had knowledge deficits regarding medication administration. Forty four percent of the clients had knowledge deficit regarding diet. Yet Redeker and Brassard (1996) found that the majority of patients experienced dysfunctional health patterns in the category of activity/exercise, which suggests the importance of nursing and collaborative interventions in this area. The major problem areas appear to be the need for assistance with activities of daily living and symptoms of weakness, tiredness, fatigue and dyspnea. Mayer, Ergina, Morin, and Gold (2003) examined functional status as a predictor of coronary artery bypass graft surgery $(\mathrm{CABG})$ outcome in elderly patients. Retrospective preoperative and postoperative geriatric assessment was obtained from 123 patients who had undergone CABG at a large urban hospital. Preoperative and postoperative health and functional status were assessed using the SF-36. Functional status was demonstrated to be a significant predictor of CABG outcome, the better the functional status prior to surgery the better outcomes after surgery. When compared with age, functional status was also found to be a more reliable predictor of CABG outcome, which had not been previously demonstrated. 


\section{Dyspnea and Functional Status}

Several studies were reviewed to determine variables that may be linked to poor functional status. The most common symptom cited in each article was dyspnea. Dyspnea, or shortness of breath, is a complex subjective sensation. The sensation of dyspnea may arise in response to a variety of afferent signals from chest wall stretch receptors, juxtapulmonary receptors in the lung, vascular receptors, chemoreceptors, and receptors in the peripheral muscle (Russell, McNeer, \& Higginbotham, 1998). In heart disease, the sensation of dyspnea can arise from abnormal stimulation of several potential pathways. With exercise, patients with heart disease have an increase in minute ventilation related to an early increase in lactate production and resultant increase in carbon dioxide flux (Russell, McNeer, \& Higginbotham, 1998). In addition, Clark, Swan, and Laney (1994) found a decrease in lung compliance in patients with heart failure.

Multiple studies (Table 1) have shown that the degree of dyspnea perceived by people directly affects their functional performances. For example, high levels of dyspnea decrease functional performance (Lee, Graydon, \& Ross, 1991; Leidy \& Knebel, 1999), improved nursing assessment skills was associated with improved symptom management of dyspnea which leads to improved functional status and perceived quality of life (Moody, McCormick \& Williams, 1991), and prevalent symptoms of dyspnea and fatigue were highly correlated with low functioning scores (Graydon, Ross, et al..1995). 
Table 1

List of studies related to dyspnea and functional status

\begin{tabular}{|c|c|c|c|c|c|}
\hline Publication & Sample & Instrument/Method & $\begin{array}{l}\text { Functional } \\
\text { status }\end{array}$ & $\begin{array}{l}\text { Variables \& } \\
\text { Covariables }\end{array}$ & Results \\
\hline $\begin{array}{l}\text { Mayor,Ergina, Morin, Gold (2003) Self } \\
\text { reported fincutional status as a predictor } \\
\text { of coronary artery bypass graft surgery } \\
\text { outcome in elderly patients. } \\
\text { Canadian Journal of Cardiology. } 19(2) \text { : } \\
\text { 140-144 }\end{array}$ & $\begin{array}{l}123 \text { CABG } \\
\text { patients. } \\
\text { Males and } \\
\text { females }\end{array}$ & SF-36 & $\begin{array}{l}\text { Pre-op and } \\
\text { post op } \\
\text { functional } \\
\text { status }\end{array}$ & $\begin{array}{l}\text { 1.Co- } \\
\text { morbidities } \\
\text { 2.Pre-op } \\
\text { function }\end{array}$ & $\begin{array}{l}\text { FS demonstrated } \\
\text { significance in } \\
\text { CABG outcomes. } \\
\text { Good pre-op } \\
\text { function significant } \\
\text { for post function }\end{array}$ \\
\hline $\begin{array}{l}\text { Mithal, Mann, Granger (2001) } \\
\text { Functional limitations and disability } \\
\text { associated with congestive heart failure. } \\
\text { Physical and Occupational Therapy in } \\
\text { Geriatrics. } 18(3): 45-56\end{array}$ & $\begin{array}{l}33 \text { frail } \\
\text { elderly males } \\
\text { and females } \\
>60 \text { years of } \\
\text { agemean age } \\
76\end{array}$ & $\begin{array}{l}\text { Lifeware Cardiac } \\
\text { Assessment Form } \\
\text { Descriptive } \\
\text { Statistics }\end{array}$ & $\begin{array}{l}\text { Fim scores } \\
\text { over } 6 \\
\text { months } \\
\text { ADL and } \\
\text { IADL }\end{array}$ & $\begin{array}{l}\text { 1.Dyspnea } \\
\text { 2.Chest pain } \\
\text { 3. Fatigue. }\end{array}$ & $\begin{array}{l}\text { Mild to moderate } \\
\text { relationship between } \\
\text { symptoms and } \\
\text { function }\end{array}$ \\
\hline $\begin{array}{l}\text { Marensson, Karsson, Fridlund (1997) } \\
\text { Male patients with congestive heart } \\
\text { failure and their conception of the life } \\
\text { situation } \\
\text { Journal of Advanced Nursing. 52: 579- } \\
586\end{array}$ & $\begin{array}{l}12 \text { male } \\
\text { patients } \\
48-80 y r s\end{array}$ & $\begin{array}{l}\text { Phenomenological } \\
\text { Study }\end{array}$ & $\begin{array}{l}\text { Physical } \\
\text { restrictions } \\
\text { Cannot work }\end{array}$ & $\begin{array}{l}\text { 1. Fatigue } \\
\text { 2. Dyspnea }\end{array}$ & $\begin{array}{l}\text { 1. Fatigue } \\
\text { 2. Dyspnea } \\
\text { 3. Isolation } \\
\text { 4. Lack of energy }\end{array}$ \\
\hline $\begin{array}{l}\text { Marensson, Karsson, Fridlund (1998) } \\
\text { Female patients with congestive heart } \\
\text { failure how they conceive their life } \\
\text { situation Journal of Advanced Nursing. } \\
28(6) \text { : 1216-1224 }\end{array}$ & $\begin{array}{l}12 \text { Female } \\
65-83 \text { yrs }\end{array}$ & $\begin{array}{l}\text { Phenomenological } \\
\text { Study }\end{array}$ & $\begin{array}{l}\text { Physical } \\
\text { restrictions }\end{array}$ & $\begin{array}{l}\text { 1.Fatigue } \\
\text { 2. Lack of } \\
\text { energy }\end{array}$ & $\begin{array}{l}\text { 1. Fatigue } \\
\text { 2. Lack of social } \\
\text { support }\end{array}$ \\
\hline
\end{tabular}




\begin{tabular}{|l|l|l|l|l|l|}
\hline $\begin{array}{l}\text { Freidman, King (1995) Correlates of } \\
\text { fatigue in older women with heart failure } \\
\text { Heart and Lung. 24(6): 512-518 }\end{array}$ & $\begin{array}{l}57 \text { women } \\
52-92 \text { yrs }\end{array}$ & $\begin{array}{l}\text { Cohen-Hoberman } \\
\text { Inventory of } \\
\text { Physical Symptoms }\end{array}$ & $\begin{array}{l}\text { Fatigue } \\
\text { caused } \\
\text { decline in } \\
\text { functional } \\
\text { status }\end{array}$ & $\begin{array}{l}\text { 1. Dyspnea } \\
\text { 2. Chest pain }\end{array}$ & $\begin{array}{l}\text { Fatigue primary } \\
\text { symptom related to } \\
\text { decline in functional } \\
\text { status. }\end{array}$ \\
\hline $\begin{array}{l}\text { Moore (1995) A comparison of women's } \\
\text { and men's symptoms during home } \\
\text { recovery after coronary artery bypass } \\
\text { surgery }\end{array}$ & $\begin{array}{l}20 \text { women } \\
\text { Heart and Lung. 2496): 495-501 }\end{array}$ & $\begin{array}{l}\text { collected data } 48 \\
\text { hours after } \\
\text { discharge and then } \\
3 \text { weeks }\end{array}$ & $\begin{array}{l}\text { Limited } \\
\text { ability to do } \\
\text { ADL and } \\
\text { IADL }\end{array}$ & $\begin{array}{l}\text { 1. Fatigue } \\
\text { 2. Low } \\
\text { energy level } \\
\text { 3. Dyspnea }\end{array}$ & $\begin{array}{l}70 \% \text { of women able } \\
\text { to do housework } \\
\text { after } 3 \text { weeks } \\
0 \% \text { men }\end{array}$ \\
\hline $\begin{array}{l}\text { Cho, Alessi, Cho, Aronow (1998) The } \\
\text { association between chronic illness and } \\
\text { functional change among participants in } \\
\text { a comprehensive geriatric assessment } \\
\text { program } \\
\text { Journal of American Geriatrics Society. } \\
\text { 45(6): 677-682 }\end{array}$ & $\begin{array}{l}202 \text { men and } \\
\text { women } \\
\text { Mean age } 81\end{array}$ & $\begin{array}{l}\text { Functional status } \\
\text { assessed at baseline } \\
\text { and annually for 3 } \\
\text { years } \\
\text { Structured } \\
\text { Functional status } \\
\text { questionnaire }\end{array}$ & $\begin{array}{l}\text { ADL and } \\
\text { IADL } \\
\text { Varied per } \\
\text { individual }\end{array}$ & $\begin{array}{l}\text { 1. gait } \\
\text { disorder } \\
\text { 2. depression } \\
\text { 3. unsafe } \\
\text { home } \\
\text { environment } \\
\text { 4. CAD } \\
5 \text {. dyspnea }\end{array}$ & $\begin{array}{l}\text { Fatigue } \\
\text { Gait disorder }\end{array}$ \\
\hline
\end{tabular}




\section{Significance}

The majority of the studies conducted with patients experiencing a cardiac disease in the home health setting deal with limiting readmission to the hospital. There are very few studies that look at patients with cardiac disease and the need to improve functional status to allow the patient to be more independent in their home. Indeed, with increased independence at home will cardiac patients have fewer hospitalizations with exacerbation of the disease process? OASIS is an important tool to utilize to study this phenomenon.

Outcomes for most OASIS measures are analyzed along two axes: improvement and stability. For each measurement, outcomes are aggregated and analyzed at the agency level. The total percentage of positive outcomes achieved for each measure is used as a benchmark of agency performance. Agencies then compare their performance with their own previous performance and that of other agencies. Each agency then picks certain indicators where the scores declined and develops strategies to improve that indicator. While OASIS provides a picture of agency performance, it does not, as currently utilized 1) indicate patient level outcomes of care over a broad group of measures, 2) group patients per diagnostic and 3) look at outcomes, or indicate patient's improvement or decline and which factors affected them. Currently, agencies are developing strategies to improve scores of the aggregate instead of the patient outcomes OASIS provides an excellent source for outcome data for two reasons: First, it has been developed as an outcome measurement tool specifically designed for use with home health patients and second it is now mandated by CMS for use by all Medicare and Medicaid certified home health agencies, thus it can be expected to be a rich source of data on home health services utilization and outcomes. The development of methods for 
analyzing and utilizing this data will be an important aspect of health services research in the home health sector for the future. This study is significant because OASIS needs to be deconstructed to determine if home health care is effective for a specific diagnostic group of patients.

Annual OBQI outcome reports for home health agencies are available for all Medicare certified home health agencies nationally and this is a resource for physicians, case managers, discharge planners and savvy patients to make referrals or chose certain home health agencies. These will also be used by Medicare to monitor patient outcomes which then may trigger the state survey process for the home health agencies (Shaughnessy, Hittle, Crisler, Powell, Richard, et al., 2002). 


\section{CHAPTER 3}

\section{Methodology}

The purpose of this study was to examine whether the functional status (ADLs and IADLs) in patients with a primary diagnosis of cardiac disease improved with home care. The variables of dyspnea and service were examined to determine their relationship with functional status. The Quality Health Outcomes Model suggests that a reciprocal interaction occurs among the four constructs of system characteristics, interventions, client characteristics and outcomes. In this study the four constructs are operationalized as a medicare home health agency (system characteristic) home health care (interventions), patients with a primary diagnosis of cardiac disease (client characteristics), and changes in functional status (outcome). This chapter provides a detailed description of the research design, sample and sampling, instrumentation, data collection procedures, and data analytic techniques. The protection of human subjects and study limitations are also discussed.

\section{Research Design}

A descriptive correlation design was used for this study. A descriptive correlational study is defined as a study conducted in a naturalistic setting without any 
attempt to modify, control, or introduce something new to the environment (Kerlinger \& Lee, 2000). Descriptive designs are employed when the researcher wishes to obtain information in areas in which little previous investigation has occurred (Kerlinger \& Lee, 2000). Although the OASIS has been used to determine outcomes of home health services, it has been at the aggregate rather than at the individual level. A review of the literature found no one has de-aggregated the scores to determine outcomes for specific patient groups such as disease process, age, or gender. Rather each home health agency's aggregate scores are posted on the Internet for consumers, discharge planner and physicians to compare and shop for home health agencies. Agencies are required to improve their outcomes in total rather than looking at specific disease process, the age of the patients, or other individual criteria that might represent barriers to improvement in overall outcomes. Using data from a freestanding urban home health agency, this study examined functional status outcomes of cardiac patients for whom OASIS admission and discharge data were available. The dependent variable of interest is patient's post treatment functional status.

\section{Home Health Care/Intervention}

Home health care interventions may have a single discipline involved or a multitude of disciplines treating and teaching the patient. To be referred to a certified home health agency the patient must have a precipitating event in their health status. A precipitating event means either the patient has been hospitalized or there has been a change in health status requiring some type of skilled need of a Registered Nurse (RN), Physical Therapist (PT), or Speech Therapist (ST). Generally it is the RN who is the first discipline to see and assess the patient. Depending on her/his assessment and with 
the agreement of the physician other disciplines are referred or not referred. This means that nurses and therapists must have an extensive working knowledge of psychosocial and environmental factors that may be barriers to the medical care plan. In consultation with the physician each discipline determines the frequency and duration of home care visits. Visit frequency and duration may change depending on patient status during the duration of home care.

Nursing visits are the most common service in home health care, followed by home health aides and therapy (physical and occupational). Patients are seen frequently at the start of care, sometimes daily or even twice daily, but the intensity rapidly tapers in most cases. Home-health nurses provide periodic services to patients in their homes. After assessing patients' home environments, home-health nurses care for and instruct patients and their families. Home-health nurses care for a broad range of patients, such as those recovering from illnesses and accidents, cancer and dementia and must be able to work independently (Murkofsky, Phillips \& McCarthy, 2003). Additional services referred by the physician and nursing may include home health aide, physical therapy, occupational therapy, speech therapy and social work. The number of visits per discipline was examined to determine if there was a correlation with functional status. These data included the number of visits made by each discipline.

\section{Sample and Sampling}

The sample for this study included 162 patients admitted with a primary or secondary diagnosis of cardiac disease, who received treatment between January 2003 to December 2004 and for whom admission and discharge data was available. When patients had multiple admissions during this time period, only data from the first 
admission and discharge was utilized because of the possibility that response to treatment may be influenced by previous treatment experiences. Exclusion criteria included any patient who was re-hospitalized within the first 60 days (or one certification period) or patients with a diagnosis of psychosis. Hospitalized patient were excluded because there is an interruption of their care and a possible decline in functional status therefore discharge data may be compromised and patients with a secondary diagnosis of psychosis may have psychological complications that may influence their progression of care.

Because the treatment experiences, including diagnosis, interventions and outcome, are different for shorter than longer stay patients, a decision was made to restrict the sample by length of stay. The first certification period, which is 60 days, was chosen because of the significance of 60-day period of treatment in home health services. Within the first certification period a patient can be discharged at any time and the discharge OASIS is completed. OASIS data is collected every 60 days if a patient stays on service for more than one certification period. Therefore, patients who are recertified, meaning an OASIS document is filled out and sent to Medicare and the patient has a second 60 day period to receive home health services, were included in the study but the recertification OASIS was used as the second point of contact for the data (as the discharge OASIS is used for non recertified patients). Medicare prospective payment system (PPS) for home health agency services determines payment based on 60-day periods of treatment. Thus collecting data based on a 60-day length of stay is attractive because of the general significance of 60-day treatment periods in home health as well as the fact that the great majority of cases could be retained. 


\section{Sample Size}

Even though every subject who met the inclusion criteria between January 1, 2003 and December 31, 2004 would be included in the study, to determine the minimum sample size required for this study, it was necessary to select the desired power and effect size. Power reflects the probability that the statistical test would result in rejecting the null hypothesis when it is false (Munro, 2005). Cohen (1987) recommended a power of .80 for behavioral sciences. The power of a test is influenced by the effect size, which represents the difference between the groups or the strength of the relationship between variables. The larger the effect size, the greater the power of the test. The number of independent variables measured also influences the effect size with the more variables compared to subjects; the smaller the effect size would be (Munro, 2005). Behavioral science research generally utilizes a moderate effect size (0.50). Munro (2005) suggests that the effect size should be based upon previous studies, if possible. For the purpose of this research, the level of significance was set at 0.05 , the power at .80 , and the desired effect size at .50. Using sample size table provided by Hinkle, Wiersma, and Jurs (2003) the minimum number of subjects needed for this study was 158 .

\section{Data Collection Procedures}

Data was collected through a retrospective audit of home care records in a freestanding urban home health agency in San Diego County. This agency has been in operation since 1995 as a certified medicare home health agency and has been collecting OASIS data since 1999. Between 2000 and 2004 the agency has employed 20 registered nurses who have been trained and mentored in the collection of the OASIS data. Of these nurses, $75 \%$ are associate degree graduates and $25 \%$ have a Bachelor of Science degree. 
Fifty per cent of the nurses had worked in home health prior to the implementation of OASIS. Two of the registered nurses have been with the agency from 2000 to 2004; the other 18 have worked for varying intervals during the 4 year period.

Upon hire each registered nurse is given an extensive orientation to home care and documentation. Through a series of evaluations by the nurse manager and experienced home health registered nurses the orientee is trained in the use of OASIS and home health care interventions. The orientee continues in orientation until he/she can consistently fill out the OASIS document accurately and implement interventions correctly. Every two weeks all patients are discussed during interdisciplinary team conference and any discrepancies and changes in patient status are caught during this process.

\section{Measurement}

The Outcome and Assessment Information Set (OASIS) includes items developed, tested, and refined over the past decade through a research and demonstration program funded largely by the Health Care Financing Administration (HCFA) now called Center for Medicare and Medicaid Services (CMS), the Robert Wood Johnson Foundation and the state of New York (OASIS, 1998). The OASIS was designed for the purpose of enabling the rigorous and systematic measurement of patient home health care outcomes, with appropriate adjustment for patient risk factors affecting those outcomes. Outcomes derived from the OASIS measure changes in a patient's health status between two or more time points. The OASIS items address sociodemographic, environmental, support system, health status, functional status and health service utilization characteristics of the patient. The OASIS is administered at the start of care, at 60-day 
follow-up assessment, and at discharge (GAO, 2001). For the purpose of this study only the start of care and a second time frame was used, either 60 day follow up assessment or discharge.

The development of the OASIS included an initial set of 500 patient health status outcomes that were specified after reviewing the outcome and long term care literature (OASIS, 1998). Unstructured discussions were conducted with clinicians from all disciplines involved in home health care as well as representative of regulatory and governmental programs on appropriate and useful patient outcomes. Home health providers were also surveyed on these outcomes. The draft set of outcomes were refined through several rounds of external review by a total of 20 researchers in the long term care field and 20 nationally recognized clinical experts from various disciplines involved in home care (GAO, 2001; Shaughnessy \& Hittle, 2002). The multiple clinical and research panel reviews were designed to evaluate each outcome in terms of (1) validity as a quality indicator, (2) clinical utility for monitoring and improving care, (3) importance to patient health and well being, and (4) expected measurement precision (GAO, 2001). There are three domains covered in OASIS, they are clinical, functional, and service. Based upon the aims of this proposed study, the functional domain is of interest.

\section{Dependent Variable}

The dependent variable of functional domain consists of activities of daily living (ADLs) and instrumental activities of daily living (IADLs). The functional domain has good internal consistency with a Chronbach alpha rating of 0.86 at admission and 0.91 at discharge (Shaughnessy \& Hittle, 2002). A reliability coefficient of .80 or higher is considered as acceptable in most social science applications and Nunnaly (1978) has 
indicated .70 to be an acceptable reliability coefficient. The intrarater reliability was reported by Cohen's kappa, which examines the agreement between the rater at the two data collection time points (the raters included two registered nurses trained in using the OASIS who did duplicate assessments within 24 hours of one another, while randomizing which rater went first for 66 patients from five agencies). The functional domain admission kappa range is from 0.41 to 1.00 and the discharge items had a kappa range of 0.67 to 1.00 (Shaughnessy \& Hittle, 2002). Kappa has a range from $0-1$, with larger values considered better reliability. Generally a kappa score of $>.70$ is considered satisfactory (Kerlinger \& Lee, 2000). The intrarater reliability is much lower at admission than discharge. There are several possible explanations for a lower kappa score for admit verses discharge. The first reason reflects the level of expertise of the nurses doing the admission OASIS and how cooperative the patient is in answering questions and performing tasks for ambulation, transfer, and meal preparation etc. Secondly, the timing of the assessment is important because patients can be more fatigued in the afternoon as opposed to the morning, and it is not clear if the assessments were done at exactly the same time on the second day. The third reason for the differences may be due to how the nurse conducted the assessment, was the assessment done on patient self reporting or nurse observation of the patient with ambulation, transfer, toileting, bathing etc. Finally, assessments were conducted up to 24 hours apart, which leads to the question did the patient become more ill or did coming home motivate the patient to do more thus a reason for the low kappa score at admission.

Construct validity, for the OASIS functional domain was supported through factor analysis. The admission functional domain items loaded onto one factor with 
factor loadings that were all greater than $0.61 ; 56.3 \%$ of the variance was explained. The discharge functional domain items also loaded onto one factor and again all the factor loadings greater than 0.74 with $68.9 \%$ of the variance explained (Madigan \& Fortinsky, 2000).

The primary focus of this study is the change in functional outcomes of patients with a diagnosis of cardiac disease after having received home health services. Seventeen measures on the OASIS instrument which include ADLs and IADLs ( M0640, M0650, M0660, M0670, M0680, M0690, M0700, M0710, M0720, M0730, M0740, M0750, M0760, M0770, M0780, M0790, M0800) represent patient's functional status and were used to compute the overall functional status variable.

Functional status was computed by combining items related to activities of daily living (ADL) and instrumental activities of daily living (IADL). An ADL is primary activities of daily living such as bathing, grooming, toileting, dressing, transfers, ambulation, and eating. IADLs are preparing a meal, transportation, laundry, housekeeping, shopping, the use of the telephone, and management of medications. These variables were based on scores on a scale consisting of 17 OASIS measures representing different dimensions of functional status. With pre-treatment functioning serving as a control for selection bias associated with functional change, post-treatment functioning represents outcomes of care, specifically, the difference between patient's functional status entering treatment and their functional status on discharge. This data is collected at admission and discharge. Scores for each of these items are calculated on an scale of 0 to 2,0 to 3,0 to 4 , or 0 to 5 (depending on the specific item), with 0 
representing complete independence and the highest value for each item representing complete dependence or disability.

In order to construct a scale consisting of items of equal weight each score was be recoded using a scale of 0 to 100 . For example, a question that was scored at $0-4$ equaled $0=0,1=25,2=50,3=75,4=100$, whereas a question scored $0-5$ was rescored $0=1,1=20$, $2=40,3=60,4=80,5=100$. These scores were also recoded to reverse the direction of the scoring so that 100 represented complete independence and 0 represented complete dependence or disability and was done to maximize clarity in interpreting results (Keepnews, Capitman, \& Rosati, 2004).

\section{Independent Variables}

Sociodemographic variables were collected from the admission OASIS, for the purpose of describing the sample and to explore correlational relationships with the dependent variable of functional status with such demographics as age, gender and ethnicity. Ethnicity is classified on the OASIS as American Indian or Alaska Native, Asian, Black or African American, Hispanic or Latino, Native Hawaiian or Pacific Islander, White and Unknown and for this study was recorded as a single categorical variable with patients assigned to one racial or ethnic category only. The dichotomous variable of living alone or with a caregiver is important information and was also collected from the admission OASIS. Cardiac disease was stratified into four categories, congestive heart failure (CHF), coronary artery disease (CAD), hypertension (HTN), and cardiac arrthymias. This allowed the investigator to use the disease process as an independent variable. 
Table 2. OASIS Patient Functional Status Items

\begin{tabular}{|c|c|c|}
\hline Item Number & Functional Status Item & Score \\
\hline M0640 & Grooming & $0-3$ \\
\hline M0650 & Ability to dress upper body & $0-3$ \\
\hline M0660 & Ability to dress lower body & $0-3$ \\
\hline M0670 & Bathing & $0-5$ \\
\hline M0680 & Toileting & $0-4$ \\
\hline M0690 & Transferring & $0-5$ \\
\hline M0700 & Ambulation/Locomotion & $0-5$ \\
\hline M0710 & Feeding or Eating & $0-5$ \\
\hline M0720 & Planning or preparing light meals & $0-2$ \\
\hline M0730 & Transportation & $0-2$ \\
\hline M0740 & Laundry & $0-2$ \\
\hline M0750 & Housekeeping & $0-4$ \\
\hline M0760 & Shopping & $0-3$ \\
\hline M0770 & Ability to use the telephone & $0-5$ \\
\hline M0780 & Management of Oral Medications & $0-2$ \\
\hline M0790 & Management of Inhalation medications & $0-2$ \\
\hline M0800 & Management of Injectable medications & $0-2$ \\
\hline
\end{tabular}


The independent variables of dyspnea and service were also measured. The health status variable of dyspnea was recorded for all patients in the study. This variable was scored $0-4 ; 0$ indicating no shortness of breath and 4 indicating patient is continuously short of breath. Service was measured by the number of visits by each discipline during the home health intervention.

\section{Procedure}

A retrospective chart review was conducted to examine home health documentation for patients with a diagnosis of cardiac disease as their primary or secondary diagnosis from January 1, 2004 to December 31, 2004. The Oasis document requires the identification of a primary diagnosis (M0230) and secondary diagnosis (M0240) and was used to identify patients with a diagnosis of cardiac disease. A chart abstraction form was developed and used to extrapolate the data from the records. These data included demographics, diagnosis, respiratory status, and ADL/IADL status from admission and diagnosis, respiratory status, and ADL/IADL status from discharge. The total number of visits from each discipline was recorded for each patient. Confidentiality was maintained by assigning a number for each patient in the study. There was one file with patient name and the patient's assigned number for the study which was stored in a password-protected file within the principal investigator's computer. The principal investigator has completed the human subjects tutorial given by the National Institute of Health and collected all of the data. The type of data collected makes it very difficult to identify any specific individual that may have been treated at the home health agency between January 1, 2004 and December 31, 2004. The functional scores were hand coded by the principal investigator. 


\section{Data Analysis}

Secondary data analysis using descriptive and multivariable statistics were conducted on retrospective chart abstracted data from January 2003 to December 2004. The statistical package for Social Sciences (SPSS Version 14.0) was used to perform the analysis of data. All subjects who met the delimitations of the study sample were included in the analysis of data. Descriptive statistics were used to summarize the demographic variables of age, gender, race/ethnicity, financial status and living situations. Ten percent of the records were randomly selected and coded by a research assistant to assess for reliability of the chart abstraction. Ten percent of the data inputted in SPSS were checked for accuracy and reliability by a research assistant prior to running the data through SPSS.

Aim \#1: Examine functional status in patients with a primary/secondary diagnosis of cardiac disease from admission to discharge in the home health setting.

The null hypothesis is there is no change in functional status from admission to discharge for patient with the diagnosis of cardiac disease in the home health care setting.

A paired $t$-test was preformed for the total admission functional status and the total discharge functional score. The $t$ test is a statistical method for comparing differences between two groups. The test requires a continuous dependent variable on which the groups are being compared. The test assumes that the variable is normally distributed in the populations from which the samples are drawn and that the samples have equivalent variances (Munro, 2005). A paired t-test is used to compare means on the same subjects across time with some intervention occurring, thus it is a test that the 
differences between the two observations is 0 . If the two groups being compared are matched or paired on some basis, the scores are likely to be similar. The change difference between the two groups will not be as large as when they are drawn independently. In the paired t-test a correction is made that has the effect of increasing $t$, thus making it more likely to find significance (Munro, 2005). For a paired $t$ test, the data is dependent, i.e. there is a one-to-one correspondence between the values in the two samples.

Aim \#2: Examine the relationship between the independent variables of age, gender, race, primary diagnosis, secondary diagnosis, dyspnea, service, functional status at admission and the dependent variable of discharge functional status.

A correlational matrix was constructed to identify relationships between the independent variables and the dependent variables as defined in the measurement section. The correlation is one of the most common and most useful statistics. A correlation is a single number that describes the degree of relationship between two variables. In probability theory and statistics, correlation, also called correlation coefficient, is a numeric measure of the strength of linear relationship between two random variables (Munro, 2005).

Aim \#3: Examine the effect of dyspnea and service (while controlling for age, gender, ethnicity, primary diagnosis, secondary diagnosis, and admission functional status) on discharge functional status in patients with primary diagnosis of cardiac disease in the home health setting 
A multicollinearity test was conducted on the independent variables initially to determine if a relationship exists between the independent variables and if one exited how strong the relationship was. Multicollinearity is a problem that arises when there exists moderate to high intercorrelations among predictor or independent variables to be used in a regression analysis. The underlying problem of multicollinearity is that if two variables are highly correlated, they are essentially containing the same information and are therefore measuring the same thing. The simplest method for diagnosing multicollinearity is to examine the correlation matrix for predictor variables, looking for moderate to high intercorrelations (Mertler \& Vannatta, 2005). If multicollinearity is noted the researcher will make a determination which of the independent variables will be used in the multiple regression. A review of the matrix found no multicollinearity between the independent variables.

Then multiple regression was conducted using the independent variables of 1 ) dyspnea at admit, 2) dyspnea at discharge, and 3) service while controlling for 4) age, 5) gender, 6) ethnicity, 7) primary diagnosis, 8) secondary diagnosis, 9) admission functional status, on the dependent variable of discharge functional status . Multiple regression is an analytic strategy used for explanation and prediction. It is one of the most powerful techniques in studying many problems related to human behavior and the health profession (Munro, 2005). Regression analysis procedures have as their primary purpose the development of an equation that can be used for predicting values on some dependent variables for all members of a population. In standard multiple regression all independent variables are entered into the analysis simultaneously. The effect of each independent variable on the dependent variable is assessed as if it had been entered into 
the equation after all other independent variables had been entered. Each independent variable is then evaluated in terms of what it adds to the prediction of the dependent variable (Mertler \& Vannatta, 2005).

\section{Limitations}

Several limitations inherent in this study design must be acknowledged. This study does not include a randomized selection of subjects, control over environment, or manipulation of variables. Threats to external validity is the restriction to race, the majority of subjects were Caucasian, which limits the generalizability of the study results. Threats to internal validity related to the measurement approach include use of the medical record, compiled and completed by various individuals other than the investigator as the source of data.

When researchers engage only in analysis of secondary data, there is little or no appreciation of the underlying strengths and weaknesses of the data to which they may apply highly sophisticated analytic tools. These strengths and weaknesses often stem from problems in the data collection process, which may be opaque when looking at a secondary data set. For example, error and bias in survey data arise from problems of sampling, response rates, the nature of questions and the interview process, and data coding and entry procedures, but little of this information is provided with secondary data.

\section{Human Subjects}

In order to ensure the protection of each subjects freedom from intrinsic risk or injury, and to ascertain rights to privacy and dignity, a variety of human subject protective mechanisms were utilized in this study. The proposal was submitted to and 
approved by the Institutional Review Board at University of San Diego and the CEO and board members of Excel Home Health. Excel Home Health Board Members and the CEO granted permission for the collection and study of the data from patient charts from January 1, 2004 to December 31, 2004 (See appendix C). Information recorded by the investigator was done in such a manner that the subjects cannot be identified directly or through identifiers linked to subjects. Anonymity was maintained in that individual names and individual characteristics were not presented, and data analysis expresses group information, not individual information.

There are no perceived potential physical, psychological, or social risks to the subjects in this study. The findings will be used to enhance current knowledge relating home health intervention for patients with cardiac disease and functional status. 


\section{Chapter 4}

\section{Results}

The purpose of this study was to: (1) examine functional status in patients with a primary diagnosis of cardiac disease from admission to discharge in the home health setting, and (2) examine the effect of dyspnea and service on functional status. Secondary data analysis using descriptive and multivariable statistics was conducted on retrospective chart abstracted data collected from the home health records of patients diagnosed with cardiac disease and receiving home health care, from January 2003 to December 2004 In this chapter the study findings are presented. A description of the sample population is provided first, with descriptive statistics for the dependent and independent variables presented next, followed by the results related to hypothesis testing. Finally, incidental data analysis will be presented as possibilities for further study.

\section{Characteristics of the Sample}

The demographic portion of the chart abstraction form (Appendix A) was used to extrapolate subject demographic and personal data and was designed to collect information from which a profile of the sample could be developed. These data included age, gender, ethnicity, referral base, conditions prior to admit, high risk factors, living situation, caregiver assistance, diagnosis, number of medications, mean total number of 
service visits and number of visits by disciplines. The sample consisted of 654 patients but only 162 cardiac patients who received home health care services from January 2003 to December 2004 and had a completed admission and discharge OASIS were included in the sample for testing the hypotheses. Table 3 summarizes through frequency distributions the characteristics of the sample.

Participants in this study ranged in age from 60 to 98 years, the mean age was 81.32 years and was predominately female $(64.2 \%)$. To characterize diagnosis, cardiac disease was stratified into four categories, congestive heart failure $(\mathrm{CHF})$, coronary artery disease (CAD), hypertension (HTN), and cardiac arrthymias. Within the sample, $25.9 \%$ had hypertension, $35.8 \%$ were diagnosed with $\mathrm{CHF}, 24.7 \%$ had CAD and 14.8 had some type of heart arrhythmia. The sample was predominately Caucasian (80.9\%); other participants were Hispanics (6.2\%) African Americans (4.9\%) and Asians (5.6\%), and 2.4\% identified themselves as American Indian, Alaska Native, Native Hawaiian or Pacific Islander. The majority were discharged from the hospital prior to home health services $(58.6 \%)$, while the second largest group of patients were referred by a physician without an inpatient hospitalization (36.4\%). Specific information called "conditions prior to admit" was collected as well during the admission process on all patients and included incontinence, pain, impaired decision making, memory loss, or none of the above. Seventy-two percent of the sample population had none of the conditions prior to admission. Information regarding high risk factors was also collected at admission for all medicare home health patients and included such factors as smoking, obesity, alcohol dependency, drug dependency, or none of the above. Within this sample $85 \%$ had none of these high risk behaviors. 
Table 3

Summary of Demographic and Study Variable Characteristics

Characteristic

No. of cases

$\%$ of total

Age in years

60-69

13

70-79

35.4

80-89

66

39.6

$90-98$

24

14.4

Gender

Female

104

64.2

Male

58

35.8

Ethnicity

Caucasian

80.9

Hispanic

10

6.2

African American

8

Asian

9

5.6

Other

4

2.4

Referral base

Hospital

95

58.6

Home

59

36.4

SNF \& Rehab Facilities

7

4.3 
Conditions prior to admit

Incontinence $\quad 19$

Impaired decision making $\quad 24$

Memory Loss

18

Pain

3

15.3

None of the above

High risk factors

Obesity

Smoking

Alcohol \& drug dependency

0

None of the above

Residence/assistance

Own home

Family member residence

Board and care

Lives with spouse/significant other 36

Lives with paid help

50

30.9

Lives with family member

42

Assisted by family 56

Assisted by person in home 64 34.6

Assisted by paid help 79

49.1 
Caregiver and assistance level

Spouse of significant other

Daughter or son

Other family member

Paid help

Receives help day $\&$ night

Receives help during day

Once a day

3 or more times a week

ADL assistance

Note. $N=162$.

Living conditions and primary caregiver are important considerations when developing a plan of care for a home health patient. This data is collected at start of care for all patients referred to a certified home health agency. Within this sample $58 \%$ lived in their own residence and $43.4 \%$ either lived alone or with their spouse. The remainder either lived with family members $(25.9 \%)$ or with paid help (30\%). The majority required some type of assistance in the home (97.5\%) with almost fifty percent reporting paid help in the home (49.1\%), and the next largest group received assistance from a person residing in the home (39.8\%), spouse, significant other or roommate. Relatives, friends or neighbors assisted the rest of the sample (34.6\%). The primary caregiver appears to be a family member, $12.7 \%$ are cared for by spouse or significant other, $29.3 \%$ 
are cared for by daughter or son, and $7.0 \%$ by other family member. Over a third $(36.3 \%)$ utilizes paid help for assistance. Slightly less than half (48.6\%) population receives help several times during the day and night and the next largest group (35.4\%) receive help several times during the day. Assistance with ADLs are required by $58 \%$ and $95.1 \%$ require assistance with IADLs.

Table 4 presents descriptive statistics for number of medications per patient, the number of total home visits, and those broken out by service for this sample. The mean number of medications per patient was 10.52 (SD 4.17). The mean total number of visits for each patient was 10.66 (SD 8.049) and the mean total for RN visits for each patient was 6.06 (SD 4.77). The next largest number of visits was physical therapy with a mean of 3.04 (SD 3.77).

Table 4

Means and Standard Deviations for number of medications per patient, the number of total home visits by service Variable Mean (Standard Deviation) Range

Number of medications $10.52(4.17)$ $2-23$

Number of total home visits $10.66(8.049)$ $2-53$

Registered Nurse $6.06(4.77)$ $1-28$

Physical Therapy $3.04(3.77)$ $0-19$

Social Worker $0.71(1.33)$ $0-7$

Speech Therapist $0.06(.503)$ $0-6$

Occupational Therapist $0.54(1.65)$ $0-9$

Home health aide $0.46(2.11)$

$0-19$

Note. $\mathrm{N}=161$ 


\section{Descriptive Findings}

The primary focus of this study is the change in functional outcomes of patients with a diagnosis of cardiac disease after having received home health services. Functional outcomes was measured with the OASIS functional scale, which is comprised of items related to activities of daily living (ADL) and instrumental activities of daily living (IADL). An ADL is primary activities of daily living such as bathing, grooming, toileting, dressing, transfers, ambulation, and eating. IADLs are preparing a meal, transportation, laundry, housekeeping, shopping, the use of the telephone, and management of medications. With pre-treatment functioning serving as a control for selection bias associated with functional change, post-treatment functioning represents outcomes of care, specifically, the difference between patient's functional status entering treatment and their functional status on discharge.

Reliabilities for the functional domain from the OASIS data set were calculated using a Cronbach's alpha coefficient. Cronbach's alpha is a measure of internal consistency of the instrument. Cronbach's alpha measures how well a set of items (or variables) measures a single unidimensional latent construct. Cronbach's alpha is not a statistical test, rather, it is a coefficient of reliability (or consistency) and it can be written as a function of the number of test items and the average inter-correlation among the items The higher the number of items being tested the higher the Chronbach score. (Nunnelly, 1994) The reliability of the functional domain found in this sample was 0.873 at admission and 0.9 at discharge and is consistent with the reliabilities of 0.86 at admission and 0.91 at discharge reported by Shaughnessy and Hittle (2002) when OASIS was originally field-tested. 


\section{Findings related to Hypothesis Testing}

Aim \#1: Examine functional status in patients with a primary/secondary diagnosis of cardiac disease from admission to discharge in the home health setting.

The null hypothesis is there is no change in functional status from admission to discharge for patient with the diagnosis of cardiac disease in the home health care setting.

A paired $t$-test was preformed for the total admission functional status scores and the total discharge functional scores. There was a significant change in functional status from admit to discharge $(\mathrm{p}=0.000)$. (Table 5)

Table 5

T-Test for Admit/discharge Functional Status

$\underline{(N=158)}$

Paired sample statistics for Functional Status

Admission FS Discharge FS

Mean (SD)

Mean

(SD)

Mean Diff.(SD)

$t \quad(d f)$

$p$

$874.85(247.718)$

$1028.75(269.334)$

$-153.906(174.925) \quad-11.094(158) \quad .000$

Note:

FS $=$ Functional Status

$\mathrm{SD}=$ Standard Deviation

$\mathrm{DF}=$ Degrees of Freedom 
Aim \#2: Examine the relationship between the independent variables of age, gender, race, primary diagnosis, secondary diagnosis, dyspnea at admit and discharge, service, functional status at admission and the dependent variable of discharge functional status.

A correlational matrix was computed to identify relationships between the independent variables (age, gender, ethnicity, primary diagnosis, secondary diagnosis, admit functional outcome score, dyspnea at admission, dyspnea at discharge, total \# of visits) and the dependent variable of discharge functional outcome score

Pearson Product Moment correlations for the descriptive variables and functional status at discharge are presented next to examine the relationship among them (see Table 6). There was a high positive correlation between admission functional status score and discharge functional status score $(r=0.774, p=0.010)$. The correlation coefficient provides not only a measure of the relationship between variables but also an index of the proportion of individual differences in one variance that can be associated with the individual differences in another variable (Hinkle, Wiersma, \& Jurs, 2003). The correlation coefficient of 0.774 also suggests that factors other than admission scores for functional status could contribute to the discharge scores for functional status. Also of note is a weak inverse correlation between dyspnea at discharge and discharge functional status scores $(r=-0.158, p=0.05)$, service and discharge functional status scores $(r=$ $0.208, p=0.01$ ), and a moderate inverse correlation between age and discharge functional status scores $(r=-0.308, p=0.01)$. This suggests that less dyspnea at discharge is related to improved functional status scores, the younger the patient the 
greater the functional status score, and finally the fewer number of visits the patient receives is related to improved functional status scores.

Table 6

Pearson Product Moment Correlations Coefficients between Functional Status at Admission, Primary Diagnosis, Secondary Diagnosis, Dyspnea, Service, Age, Gender, Race/Ethnicity, and the Dependent Variable Discharge Functional Status

Variables

Admission Functional Status

Primary diagnosis

Secondary diagnosis

Dyspnea at admission

Dyspnea at discharge

Service

Age

Gender

Race

Note: $\mathrm{N}=162$
Discharge Functional Status

$\begin{array}{cc}\underline{\mathrm{r}} & \underline{\mathrm{p}} \\ 0.774 & 0.01^{*} \\ -0.033 & \\ 0.130 & \\ -0.022 & \\ -0.158 & \\ -0.208 & 0.05^{*} \\ -0.308 & 0.01^{*} \\ -0.025 & 0.01^{*} \\ 0.037 & \end{array}$

Aim \#3: Examine the effect of dyspnea and service (while controlling for age, gender, ethnicity, primary and secondary diagnosis and admission functional status) on discharge functional status in patients with primary diagnosis of cardiac disease in the home health setting.

A correlation matrix was computed to examine the relationships among the independent variables. The correlation matrix was reviewed for evidence of multicollinearity. Multicollinearity is a problem that arises when there exists moderate to high intercorrelations among predictor variable or independent variables to be used in a regression analysis. The underlying problem of multicollinearity is that if two variables are highly correlated, they are essentially containing the same information and are therefore measuring the same thing. The simplest method for diagnosing 
multicollinearity is to examine the correlation matrix for predictor variables, looking for moderate to high intercorrelations (Mertler \& Vannatta, 2005). The rules for interpreting the size of the correlation coefficient are 1).90 to $1.00=$ very high correlation, 2) .70 to $.90=$ high positive correlation, 3 ) .50 to $.70=$ moderate correlation, 4) .30 to $.50=$ low correlation and 5) .00 to $.30=$ little if any correlation (Hinkle et al, 2003). The strongest correlation was between dyspnea at discharge and service $(0.302, \mathrm{p}=0.01)$ (see Table 7). For this study reported here multicollinearity was not a problem.

Table 7

Pearson Product Moment Correlations Coefficients between Functional Outcomes at Admission, Primary Diagnosis, Secondary Diagnosis, Dyspnea, Service, Age, Gender, and Race/Ethnicityy.

\begin{tabular}{|c|c|c|c|c|c|c|c|c|c|}
\hline & $\underset{\mathrm{a}}{\mathrm{FSA}}$ & $\mathrm{PD}_{b}$ & $\mathrm{SD}^{\mathrm{c}}$ & $\begin{array}{l}\text { Dyspnea } \\
\text { admit }\end{array}$ & $\begin{array}{l}\text { Dyspnea } \\
\text { discharge }\end{array}$ & Service & Age & Gender & Race \\
\hline $\mathrm{FSA}^{\mathrm{a}}$ & 1.0 & -.089 & .137 & $-.203^{* *}$ & -.143 & $-.285^{* *}$ & $-.032 * *$ & -.043 & -.045 \\
\hline $\mathrm{PD}^{\mathrm{b}}$ & & 1.0 & .085 & -.017 & .001 & $.216 * *$ & .035 & $0.178^{*}$ & .086 \\
\hline $\mathrm{SD}^{\mathrm{c}}$ & & & 1.0 & $-.209^{*}$ & -.170 & $-.207^{*}$ & $-.170^{*}$ & -.030 & -.051 \\
\hline Dyspnea & & & & 1.0 & $.404 * *$ & $.266 * *$ & .089 & .070 & .028 \\
\hline Admit & & & & & & & & & \\
\hline Dyspnea & & & & & 1.0 & $.302^{* *}$ & .045 & .048 & -.207 \\
\hline Discharge & & & & & & & & & \\
\hline Service & & & & & & 1.0 & .069 & -.011 & $.200^{*}$ \\
\hline Age & & & & & & & 1.0 & $.253^{* *}$ & .050 \\
\hline Gender & & & & & & & & 1.0 & -.102 \\
\hline Race & & & & & & & & & 1.0 \\
\hline Note: $\mathrm{N}=1$ & & & & & & & & & \\
\hline
\end{tabular}

A simultaneous multiple regression was conducted using the independent variables of dyspnea and service while controlling for age, gender, ethnicity, primary diagnosis, secondary diagnosis, and admission functional status, on the dependent variable of discharge functional status. Regression results indicate that the overall model 
significantly predict discharge functional status, $R^{2}=.64, R^{2}{ }_{a d j}=.619, F(9,120)=$ $24.271, p<.05$

Table 8

Model Summary Coefficients for Simultaneous Multiple Regression Analysis Full Model

Model

(Constant)

Dyspnea at admit

Admission functional status

Dypsnea at discharge

Service

Primary Diagnosis

Secondary Diagnosis

Age

Race/Ethnicity

Gender

$R^{2}$

$R^{2}{ }_{a d j}$

$F(9,120)$

$* p<.05, * * p<.01, * * * p<.001$

$$
\text { Beta }
$$

.770

$-.086$

$-.023$

.061

5.318

.955

.083

$-.054$

2.099

$-.871$

.087

12.135

1.526

.015

32.554

.245 
The $R^{2}$ from the standard multiple regression indicated that $64.5 \%$ of the variance in discharge functional status can be explained by the independent variables. A summary of regression coefficients is presented in Table 8 and indicates only two (dyspnea at admit and admission functional status scores) of the ten variables significantly contributed to the model. The inclusion of the other variables in the model does not significantly imp[rove our prediction of discharge function status over that which is achieved through dyspnea at admit and admission functional status scores

\section{Multiple Regression Using Stepwise Method}

A stepwise multiple regression was conducted next to determine which specific independent variables made meaningful contributions to the overall predictions.

Table 9

Model Summary using the Stepwise Multiple Regression Method.

$\begin{array}{llllll}\text { IV Entered } & \mathrm{R}^{2} & \mathrm{R}^{2} \text { change } & \text { Beta } & \mathrm{t} & \mathrm{p} \\ \begin{array}{l}\text { 1)Total score for } \\ \text { functional outcomes } \\ \text { at admission }\end{array} & .601 & .601 & .775 & 13.888 & .000 \\ & & & & & \\ \begin{array}{l}\text { 2) Total score for } \\ \begin{array}{l}\text { Functional outcomes } \\ \text { at admission } \\ + \text { dyspnea at admission }\end{array}\end{array} & .620 & .019 & .142 & 2.540 & .012 \\ \end{array}$

1. Predictors in the Model: primary diagnosis, secondary diagnosis, number of visits, dyspnea at admission, dyspnea at discharge, age, gender, ethnicity, (Constant), total score for functional status at admission;

2) Predictors in the Model: primary diagnosis, secondary diagnosis, number of visits, dyspnea at admission, dyspnea at discharge, age, gender, ethnicity (Constant), total score for functional status at admission, dyspnea admission

As pointed out by Monroe (2005), the stepwise solution combines the forward solution with the backward solution and therefore overcomes difficulties associated with 
each. In this solution, variables are entered starting with that which the highest correlation with the dependent variable, while the second one entered is the one that will increase the $R^{2}$ over and above that which the first variable contributed. The variables not entered in the second regression model were primary diagnosis, secondary diagnosis, number of visits, dyspnea at discharge, age, gender, and ethnicity because these variables were not significant predictors

\section{Incidental Findings}

Exploratory analyses were conducted to examine service delivery by discipline. It was found that physical therapy, registered nurse and home health aid were significant for changes in discharge functional status. In addition, patients who live with paid help were also a significant predictor for changes in functional status. Unfortunately, due to sample size limitations further analyses with the inclusion of these variables was not possible.

\section{Summary}

This chapter presented the results of the data analysis for this study in two sections. The first section presented a description of the sample and this was followed by the three specific aims of the study. 1) The null hypothesis of no change in functional status from admits to discharge for patient with cardiac disease in the home health setting was not supported. In fact, there was a significant change in functional status from admit to discharge. 2) The relationships between the independent variables and the dependent variables was examined and found that admission functional status scores were highly correlated with discharge functional status scores. Also a weak inverse correlation was found between service and discharge functional status, age and discharge functional 
status and finally dyspnea at discharge and discharge functional status. 3) An examination of potential predictors of functional status at discharge (age, gender, ethnicity, primary diagnosis, secondary diagnosis, total score for functional status at admit, total number of visits, and dyspnea) found only functional outcomes at admit and dyspnea at admit were predictors for a change in functional status. 


\section{Chapter 5}

\section{Discussion of Findings}

The purpose of this research study was to examine the change in functional status in patients with a primary diagnosis of cardiac disease from admission to discharge, in the home health setting and examine the effects of dyspnea and service on functional status. In this chapter the research design and method, data analysis, and the overall results will be summarized. In addition, implications for nursing practice, education and research will be discussed.

This study was conducted in a freestanding medicare certified home health agency. The sample of 162 patients was obtained from a retrospective record review of all patients admitted to the home health agency between January 1, 2003 and December 31,2004 who had a primary or secondary diagnosis of cardiac disease. The majority of the patients were female and Caucasian with a mean age of 81.32 . This samples demographic profile is consistent with national statistics that indicate Caucasian females aged 75 to 84 years utilized the most home health services ( $\mathrm{Chu}, 2004)$. The majority of the study sample $(49.1 \%)$ had paid help in the home which is also consistent with national statistics that indicate that elderly Caucasian females utilize formal assistance 
more than other ethnicities who utilize informal assistance in the home ( $\mathrm{Zhu}, 2004)$. Another study finding consistent with prior research was the primary diagnosis of CHF (35\%) and the use of paid help (49.1\%). Brega and associates (2002) who studied Medicare home health practices across the United States found that $61 \%$ of the home health recipients received assistance from paid help and patients with CHF were significantly more likely to receive assistance from paid help.

Another interesting descriptive piece of data was the mean number of medications of $10.66(\mathrm{sd}=4.17)$ prescribed or taken by study participants. This finding supports the recent research report from the Health Institute at Tufts-New England Medical Center (2005). With support from the Kaiser Family Foundation and the Commonwealth Fund a survey was conducted that asked participant the number of prescribed medications they were taking. A random sample of 36,901 non-institutionalized Medicare beneficiaries between July 15 and October 7, 2003 were surveyed by mail with nearly a 50\% response rate $(18,000 \pm)$. Forty-six percent of those who responded said that they took five or more prescriptions daily (Health Institute at Tufts-New England Medical Center).

The National Committee for Quality Assurance (2005) reported that polypharmacy in the elderly are responsible for many adverse effects in patients over the age of 65. In 1999 Medicare beneficiaries composed only 14 percent of the community population but accounted for more than 41 percent of prescription medication expenses (HEDIS, 2006). Adverse drug reactions occur commonly in older outpatients, with a reported prevalence ranging between 5 percent and 35 percent (Gurwitz, 2003; Hanlon, 2001). These adverse drug reactions are a major threat to the health related quality of life of older adults. Thus, reflecting upon the number of medications reported to be taken in 
conjunction with potential interactions of 10 medications plus the side effects, one could surmise medications must have some effect on functional status. Once again, due to the limited size of this study the independent variable of the number of medications was not incorporated in the multiple regression for predictors for discharge functional status.

The first aim of this study was to examine functional status (ADLs and IADLs) from admission to discharge for patient with a diagnosis of cardiac disease receiving services within the home health setting. The null hypothesis for this aim was that no change occurred in functional status from admission to discharge for patient with cardiac disease in a home health setting. The mean score for admission functional status was 874.85 (SD 247.718) and the mean score for discharge functional status was 1028.75 (SD 269.334). A paired t-test was conducted for the total admission functional score and the total discharge functional score. The mean difference in the scores was found to be significant with a $t$ score of $-11.094(\mathrm{p}=0.000)$, depicting that for this sample patient's functional status improved from admission to discharge. These results are similar to those reported by Keepnews and associates (2004) who examined the use OASIS data to analyze patient level outcomes of home health care. OASIS data was obtained on 1015 patients who received home health care services for 60 days or fewer from a large, independent home health agency between August 1998 and December 1999. Data for each of these measures were collected by the clinician and recorded on the OASIS instrument. The investigators found $78.1 \%$ of patients improved in functional status, while $18.4 \%$ declined and $2.8 \%$ showed no change. The mean score for admission functional status was of $1068.65(\mathrm{SD}=297.85)$ on admission $(66.8 \%$ of the maximum possible score) and a mean score of $1253.05(\mathrm{SD}=301.58)$ on discharge $(78.3 \%$ of 
maximum possible score). Although the patient population was not just cardiac patients but all the patients referred to the home health agency, the mean age of the population was 62 years old, and $37 \%$ did have a primary diagnosis of cardiac disease, and were overwhelmingly white females.

Dalton (2001) used OASIS to evaluate a cardiac disease management program. She examined the specific functional outcomes that were measured on admission and at discharge which included the patient's ambulation/locomotion ability, transferring ability, bathing ability, ability to prepare and take all prescribed oral medications, level of pain, level of shortness of breath, and level of anxiety. Improvement in the level of functioning was reflected in all of the patient outcomes. The client characteristics for Dalton's study were female, with a mean age 70.4 years. Overall Dalton's findings are similar to the findings reported here.

Treatment for all home health patients has the goal of returning patients to, or maintaining them at, their highest possible level of self-care and independent functioning. Whether patients are convalescing from an acute illness or suffering chronic impairment, home health treatment is aimed at allowing them to return to or remain at home, and to leave and receive treatment outside of an institutional setting. Functional health status was selected as CMS's outcome measure of choice because it was the greatest interest to Medicare beneficiaries and it reflects the agency's strategic objective of being patient centered. There was evidence that complex issues such as chronic illness, co-morbidity, and functional impairment are particular problems among the elderly and present distinct challenges to this population. It was believed that a functional status measure was an important outcome of care, due to the complexities involved in the health of older adults, 
and because of the growing concern about how managed care would affect these conditions and this population's subsequent functional status (Bierman, Lawrence, Haffer, \& Clancy, 2001). Thus measures of overall functional ability and independence are important ways to assess the efficacy of home health treatment (Keepnews, Capitman, \& Rosati, 2004). The highest score found in the study reported here, for either admission or discharge functional status was 1700 . The discharge mean functional status score was only 1028.75 , or $60 \%$ of their possible functional score. In comparison with Keepnews et al., (2004), the mean discharge functional score was lower in this study but in fairness the mean age in this study was 81 years or about twenty years older than the mean age of 62 years old reported by Keepnews and associates. It is impressive that the functional scores still improved for this aged sample, although these patients are functionally compromised.

Aim \#2 examined the correlation between the independent variables (age, gender, race, admission functional status scores, dyspnea at admit and discharge, primary and secondary diagnosis and service) and the dependent variable of discharge functional status. There was a high positive correlation between admission functional status scores and discharge functional status scores $(r=0.774, p=0.010)$. The correlation coefficient provides not only a measure of the relationship between variables but also an index of the proportion of individual differences in one variance that can be associated with the individual differences in another variable (Hinkle, Wiersma, \& Jurs, 2003). The correlation coefficient of 0.774 suggests that factors other than admission scores for functional status could contribute to the discharge scores for functional status. This 
suggests that patients who are admitted with high functional scores are closely related to being discharge with a higher functional score.

Also of note is a weak inverse correlation between service and discharge functional status scores $(r=-0.208, p=0.01)$, age and discharge functional status scores $(r=-0.308, p=0.01)$, and dyspnea at discharge and discharge functional status scores $(\mathrm{r}=-0.158, \mathrm{p}=0.05)$. This suggests that less dyspnea at discharge is related to improved functional status scores at discharge, the younger the patient the greater the discharge functional status score and finally the less number of visits the patient receives is related to improved functional status scores. It is interesting to note that this weak inverse correlation between service, age, and dyspnea at discharge was not significant as predictors for discharge functional status in the multiple regression.

Aim \#3 examined the effect of dyspnea and service while controlling for age, gender, ethnicity, primary and secondary diagnosis and admission functional status discharge functional status in patients with primary diagnosis of cardiac disease in the home health setting. A test to check for multicollinearity was conducted on the independent variables initially to determine if a relationship exists between the independent variables and if one existed how strong the relationship was. The strongest correlation was between dyspnea at discharge and service $(r=0.302, p=0.01)$ although at 0.302 there is a small to moderate (depending on the reviewer) correlation. Thus, the various independent variables included in this study were not measuring the same domain.

In the standard multiple regression, which was conducted first, independent variables were entered simultaneously. The $F(d f=160)$ was $24.271, \mathrm{p}<0.001, R^{2}=$ 
.645 ; therefore the relationship between the independent variables and the dependent variable is linear and the model significantly predicts the dependent variable (Mertler \& Vannatta, 2005). The $R^{2}$ from the standard multiple regression indicated that $64.5 \%$ of the variance in discharge functional status can be explained by the model. Dyspnea at admit and admission functional status scores were the only independent variables that were significant for predicting a change in functional status at discharge. Admission functional status scores are positively associated with improved discharge functional status scores $(B=.770, \mathrm{p}=.000)$. This suggests that patients with a higher admission functional status have fewer problems with ADLs and IADLs so their discharge functional status will improve at discharge. Dyspnea at admission is also positively associated with discharge functional status scores $(B=.191, \mathrm{p}=.002)$. This may suggest that patients with dyspnea at admission have low admission functional status scores and as the dyspnea improves so does the discharge functional status score. However, it must be noted that over $30 \%$ of the variance is not explained in this model.

A stepwise multiple regression was conducted next to determine which specific independent variables made meaningful contributions to the overall predictions. As previously noted, the biggest contributions to discharge functional scores was admission functional score, $R^{2}=.601, R^{2}$ change $=.601$, and $F=192.864(\mathrm{p}=.000)$. With the addition of dyspnea at admit the $R^{2}$ increased to $.620, \mathrm{R}^{2}$ change $=.019, F=6.451(\mathrm{p}$ $=.012$ ). It is interesting to note that age, gender, ethnicity, diagnosis, or service were not significant for discharge functional status scores.

That dyspnea at admit is related to discharge functional status scores is supported by the literature. The most commonly cited symptom for decline in functional status was 
dyspnea (Freidman \& King, 1995; Martensson, et al, 1997; Mayor et al, 2003; Mithal et al., 2001; Moore, 1995) These studies have shown that the degree of dyspnea perceived by people directly affects their functional performances. Other studies found that high levels of dyspnea decrease functional performance (Lee, Graydon, \& Ross, 1991; Leidy \& Knebel, 1999). Moody, McCormick, and Williams (1991) reported improved symptom management of dyspnea leads to improved functional status and perceived quality of life for patients. Graydon, Ross, Webster, Goldstein, \& Avendano (1995) examined 71 patients with COPD and found prevalent symptoms of dyspnea and fatigue were highly correlated with low functioning scores.

The findings in this study that admission functional status scores are significantly related to discharge functional status scores make intuitive sense. If the patient's functional status is good at admit then is seems to suggest discharge functional status will improve. Keepnews and associates (2004) also found that admission functional status scores were a predictor for discharge functional status scores. Moore (1995) examined the recovery pattern for patients who had coronary artery bypass surgery. She found those patients who were able to care for themselves prior to surgery had the higher level of self care after surgery within 3 weeks. Moore attributed this to a better level of health prior to surgery than the patients who still required significant help 3 weeks post surgery. Kramer and associates (2000) studied the outcomes and utilization difference for older persons with strokes. They also found that patients with higher level of function prior to the stroke had better outcomes and utilized fewer services than patients with poor functional status pre stroke. Wang, Van Belle, Kukull, \& Larson (2002), studied 1,873 patients with $\mathrm{CAD}$ and found that functional independence is an important component of 
quality of life. Patients self reported scores on ADL and IADL tests and patients with higher scores (meaning higher functional status) had lower age related rates of functional decline over 4 years of follow up after controlling for baseline function which translated into higher scores for quality of life.

On the other hand, the findings in this study that age, diagnosis, and service were not significant for discharge functional status scores either positively or negatively are in contrast to the prior empirical based literature. For example, Shelkey and Wallace (1998) found that normal aging changes and health problems, such as $\mathrm{CHD}$, frequently show themselves as declines in the functional status of older adults and one of the best ways to evaluate the health status of older adults is through functional assessment, which provides objective data that may indicate future or present decline or improvement in health status. Wensing, Vingerhoets, and Grol (2001) examined the relationship between functional status and age and comorbidities, and found in the multiple regression analysis age had a negative effect on functional status. In other words poorer functional status was associated with increased age. Lieberman and Lieberman (2005) reported that advanced age had a negative effect on improved functional status after the intervention of rehabilitation for stroke patients. Mithal, Mann, and Granger (2001) studied the role of Coronary Heart Disease (CHD) in functional limitation in community dwelling elders. A group of 33 frail elders with $\mathrm{CHD}$ were interviewed over a period of 6 months and the results of the correlation analysis demonstrated a mild to moderate relationship between the disease process, symptoms experienced by the elders, and their performance of day to day physical activity. 
Redeker and Brassard (1996) examined the health patterns of cardiac surgical patients in the home health care population and their relationships to outcome and duration of home health care. They specifically examined the functional and dysfunctional health patterns of cardiac surgical clients admitted to the home health care nursing service and the relationship among age, gender, health patterns, outcomes, and duration of home health care services used by cardiac surgery clients. They found that the majority of patients experienced dysfunctional health patterns in the category of activity/exercise, which suggests the importance of nursing and collaborative interventions in this area. The major problem areas appeared to be the need for assistance with activities of daily living and symptoms of weakness, tiredness, fatigue and dyspnea (Redeker \& Brassard, 1996).

Although several studies have found that home health service improve use in medications, decrease the readmission rates, and improve quality of life, few have investigated home health services and improvement in functional status. Of those published mixed findings have been presented. For example, Weaver et al., (2003) examined the effect of a more efficient home care protocol to manage total joint replacement elderly patients after surgery. Study findings indicated an increase in the functional score for both the control group (which had standard PT and RN visits) and the treatment group (home care protocol) but neither of the changes were significant. Phillips, Abrandt, Cesta, and Gallucci (1999) conducted a prospective study focused on elderly patients with hip fractures progressing from an acute rehabilitation unit to home care with and without case management. Both the control group (without case management) and the experimental group (with a case manager) showed improvement on 
their functional status scores but again the change in functional scores was not significant for either group.

Even though service (number of home health visits) was not significant to the discharge functional status score in this study, it should be further investigated and each discipline should be examined for its effect on discharge functional status. Although it appears that functional status improves with home health care as found this study and reported in previous research (Dalton, 2001; Keepnews et al., 2004), the cause of the improvement has not been identified. It may just be a function of time and the general improvement of health status after a precipitating health event or it could be related to a particular disease process (disease process was not individualized in this study) or a particular discipline in the home health setting. In the study reported here, the mean age was much higher than that found in the Keepnews et al. (2004) or Dalton (2001) studies. It would be interesting to examine the functional status scores associated with an age category to determine if the higher percentage of age of this study effected the outcomes. It is important to note that even at this advanced mean age of 81 the sample improved their functional status scores. The number of medications, which was not delineated in either of the other studies, may have an effect on outcomes, especially since the mean age of the patient is much higher in this study. Further studies need to be conducted examining cardiac disease and improvements in functional status. As the population ages so will the percentage of people with cardiac disease, so it behooves the health care researchers to make this a priority for further study. 


\section{Implications for Nursing}

\section{Nursing Practice}

Assisting older clients to maintain their optimal level of functional status is an important interdisciplinary responsibility and as the current study found, the majority of the participants were able to improve their functional status through interventions in the home health setting. Shepard (1997) suggests that with appropriate physical exercise, it is possible to resist the deleterious effects of aging which include a decline in functional status.

In this study the majority of the visits were made by the registered nurse who then make referrals to other disciplines as appropriate. This finding is similar to the national statistics that the majority of all certified home health visits are made by the registered nurse (Hill, 1999). Nursing has an important role in establishing the interdisciplinary team for each patient; therefore it will be important to continue the research in this area.

Dyspnea has an effect on improvement of functional status, therefore nursing needs to be reminded to assess dyspnea for all periods of the day, not just during the visits to determine the patient's respiratory status. Nursing has an important role to improve respiratory status during the home health intervention at the same time that OT and PT are working on functional status

The results of this study suggest that functional status improves in the home health setting and interventions are successful in improving functional status of patient with cardiac disease. Home health care is vital to allow patients to remain in their homes as independently as possible. The registered nurse plays a pivotal role in determining the interdisciplinary team and directing the team towards common goals. 


\section{Nursing Education}

Nurses are not immune to the ageist ideals prevalent in American society today. Nursing care for older adults suffers when ageist attitudes play a major factor in nursing inadequate response to the needs of the elderly (Estes, 1991). Preparation of specialized gerontological nurse at the graduate level is in decline. Haight, Christ, and Dias (1994) stated that graduate programs in the United States that specialize in gerontological nursing are in crisis. In view of these factors, it is imperative that nursing educators depict older adults in a more realistic light to improve patient care and increase the desire to specialize in the field of nursing.

There has been a significant decline in the number of nurses working in the home health field. Various reasons for this decline have been identified as home health agencies can no longer compete against the hospital pay for nursing, the addition of the OASIS document has increased the burden of paperwork, and finally time for traveling in the urban and rural setting is usually not compensated by the agency. Yet home health provides a crucial part of the continuum of health care for the elderly. Nursing education should include a specialty for home health care, or at least a sub specialty for those specializing in gerontological nursing. For undergraduate students the curriculum should include the positive aspects of home heath care and the many opportunities in the home health care settings. Hopefully this will help promote a more positive view of the home health setting and incentivize nurses to enter the field of home health care.

\section{Nursing Research}

The majority of the research in home health has been on the readmission rate of the patient into the hospital after or during the home health intervention. With the OASIS 
document becoming mandatory for all home health agencies, studies can now focus on other areas of care provided by the home health team. This study only looked at patients with cardiac disease and made the discovery that functional status improves in the home health care setting for this sample of patients. Further research with a larger population of home health cardiac patients and changes in functional status should be conducted. Additionally, each disease process can be scrutinized for changes in functional status utilizing the OASIS document. All the information from OASIS goes to the federal government, therefore a national study could be undertaken to possibly determine specific interventions for specific disease entities. Finally, it is well documented that utilization of home health is very different based on west coast, mid west, northeast, and southern geographic areas. It would be interesting to look at the outcomes for each disease process in the different areas of the United States. For example, in the south the total number of visits far exceeds the total number of visits in California (GAO, 2001), which leads one to ponder whether or not they have different patient outcomes? Further research is needed in this area.

\section{Conclusion}

Although some of the findings were not what were expected, more information about home health interventions and changes in functional status of cardiac patients has been obtained and can be added to the knowledge base of home health care. There are very few studies that look at patients with cardiac disease and the need to improve functional status which allow the patient to be more independent in their home. OASIS is an important measure that lends itself to the study of this phenomenon and to improve patient outcomes for those receiving care in the home health setting. 


\section{References}

Adams, C., \& Short, R. (1999). Rural versus urban home health: does locale influence OASIS outcomes. Outcomes Management for Nursing Practice. 3 (1): 26-32.

Ades, P., Waldman, M., McCann, W., \& Weaver, M. (1992). Predictors of cardiac rehabilitation participation in older coronary patients. Archives of Internal Medicine. 152, 1033-1035.

Alexander, R., Schlant, R., \& Fuster, V. (1998). Diagnosis and management of patients with chronic ischemic heart disease. In R. Alexander, R. Schlant and V. Fuster (Eds.) Hurst's the heart, arteries and veins. (Vol, 1, $9^{\text {th }}$ Edition) New York: McGraw-Hill Health Professions Division.

American Heart Association. (2004). 2000 Heart and stroke statistical update. Dallas, Texas: American Heart Association.

Andersen, R. (1995). Revisiting the behavioral model and access to medical care: Does it matter? Journal of Health and Social Behavior, 36, 1-10.

Anderson, P. (2000). Thrive, survive, perish: The impact of a prospective payment system on home health. Policy, Politics, \& Nursing Practice, 1, 278-283

Anderson, M, Madigan, E., \& Helms, L. (2001). Nursing research home health care endangered species. Home Care Provider, December, 201-204.

Baer, E., D’Antonio, S., \& Lynaugh, J. (2002). Enduring issues in American nursing. Springer Publishing Company: New York

Benjamin, A. (1993). An historical perspective on home care policy. Milbank Quarterly, $71,129-166$.

Benjamin, A. (1999). A normative analysis of home care aoals. Journal of Aging and 
Health, $11(3), 445-468$.

Bierman, A. (2004). Coexisting illness and heart disease among elderly medicare managed care enrollees. Health Care Financing Review, 25 (4), 105-141.

Berquist, Sandra. (2003). Pressure ulcer prediction in older adults receiving home health care: implications for use with the OASIS. Advances in Skin and Wound Care, 16 (3), 132-138.

Bishop, C., \& Skwara, K., (1993). Recent growth of medicare home health. Health Affairs, 12(3), 95-110.

Binstock, R., \& Cluff, L. (2000) Home care advances, essential research and policy issues. Springer Publishing Company, New York, NY.

Blanchard, C., Rodgers, W., Courneya, K. (2002). Self - efficacy and mood in cardiac rehabilitation: should gender be considered? Behavioral Medicine, 27(4), 149173.

Bowles, K. \& Cater, J. (2003) Screening for risk of re-hospitalization from home care: Use of the outcomes assessment information set and the probability of readmission instrument. Research in Nursing and Health, 26, 118-127.

Carville,K., \& Smith, J. (2004) A report on the effectiveness of comprehensive wound assessment and documentation in the community. Primary Intervention: The Australian Journal of wound management, 12, 41-49.

Cho, C., Alessi, C., Cho, M., Aronow, H., Stuck, A., Rubenstein, L., \& Beck, J. (1998). The association between chronic illness and functional change among participants in a comprehensive geriatric assessment program. Journal of the American Geriatrics Society, 46(6), 677-682. 
Cohen, J. (1987). Statistical power analysis for the behavioral sciences (2nd edition). Hillsdale, NJ: Erlbaum.

Coleman, B. (2000). Assuring the quality of home care: The challenge of involving the consumer. AARP Public Policy Institute. Washington DC.

Conditions of Participation (2002). Implementation manual. Department of Health and Human Services : Health Care Financing Administration.

Conditions of Participation (2004). Implementation mamual. Department of Health and Human Services : Center for Medicare and Medicaid.

Conley, V. \& Walker, M. (1998). National health policy influences on medicare home health. Home Health Care Services Quarterly, 17, 1-15.

Cowan, C., Catlin, A., Smith, C., \& Sensenig, A. (2004). National Health Expenditure, 2002. Health Care Financing Review, 25(4), 143-166.

Dalton, J. (2001). Using OASIS patient outcomes to evaluate cardiac disease management program: A case study. Outcomes Management for Nursing Practice. 5 (4), 167-172.

Donabedian, A. (1966). Evaluating the quality of medical care. Milbank Memorial Fund Quarterly, 44(part 2), 166-206.

Devitt, Neal. (1977). The transition from home to hospital birth in the United States, 1930-1960. Birth and Family Journal, 4, 47-58.

Estes, C. (1991). The aging enterprise. San Francisco: Jossey-Bass.

Estes, C., Swan, J, Bergthoid, L., \& Spohn, P. (1992). Running as fast as they can: Organizational changes in home health care. Home Health Care Services Quarterly, 16, $35-69$. 
Feldman, P., Peng, T., Murtaugh, C., Kelleher, C., Donelson, S., McCann, M., \& Putnam, M. (2004). A randomized intervention to improve heart failure outcomes in community based home health care. Home Health Care Services Quarterly, 23 (1), 1-19.

Fermazin, M., Canady, M., Milmine, P., Perron, J., \& Cooper, L. (2004). Home health compare: Web site offers critical information to consumers, professionals. Lippincott's Case Management,. 9(2), 89-95.

Fetrick, A., Christensen, M., \& Mitchell, C. (2003). Does public health nurse home visitation make a difference in the health outcomes of pregnant clients and their offspring? Public Health Nursing, 20, 184-189.

Frideman, M. \& King, K. (1995). Correlates of fatigue in older women with heart failure Heart \& Lung, 24(6), 512-518.

GAO (2001). Implementation manual. Department of Health and Human Services: Center for Medicare and Medicaid.

Gingerich, B., \& Ondeck, D. (1999). OASIS for home care organizations. Aspen Publication: Gaitherburg, Maryland.

Green, J., Grant, M., Hill, K., Brizzolara, J., \& Belmont, B. (2003). Heart disease risk perception in college men and women. Journal of American College Health, 51 (5), 1-8.

Gordon, S. (2006). What do nurses really do? Topics in Advanced Practice Nursing eJournal, 6(1).

Graydon, J., Ross, E., Webster, P., Goldstein, R. \& Avendano, M. (1995) Predictors of 
functioning in patients with chronic obstructive pulmonary disease. Heart and Lung, 24, 369-375.

Gurwitz, J., Field, T., \& Harrold, L. (2003). Incidence and prevalence of adverse drug events among older persons in the ambulatory setting. Journal of American Medical Association, 289, 1107-1116.

Haight, B., Christ, M., \& Dias, J.(1994). Does nursing education promote ageism? Journal of Advanced Nursing, 20, 382-390.

Hanlon, J., Gray, S., \& Schmader, K. (2001). Adverse drug reactions (pages 289-314). Therapeutics in the Elderly. $3^{\text {rd }}$ Ed. Cincinnati, Ohio. Harvey Whitney Books. Hawes, C., \& Kane, R. (1991). Issues related to assuring quality in home health care. Advances in Long-Term Care, I\&2, 200-251.

Hazzard, W., Blass, J., Halter, J., Ouslander, J., \& Tinetti, M. (2003). Principles of geriatric medicine and gerontology. McGraw-Hill, New York.

Health Care Financing Administration. (1998). Medicare and medicaid statistical supplement - 1998. Health Care Financing Review.

Haupt, B. (1998). Characteristics of hospice care users: 1996 national home and hospice care survey. Vital and Health Statistics of the Centers for Disease Control and Prevention. No. 299. Hyattsville, MD: National Center for Health Statistics, U.S. Department of Health and Human Services.

Hawes, C., \& Kane, R. (1991). Issues related to assuring quality in home health care. Advances in Long Term Care, 16, 200-251.

HEDIS-Health Plan Employer Data Information Set (2006). National Committee for Quality Assurance. Washington DC. 
Hill, M. (1999). Outcomes measurement requires nursing to shift to outcome-based practice. Nursing Administration Quarterly, 24, 28-36.

Hinkle, D., Wiersma, W., \& Jurs, S. (year). $5^{\text {th }}$ ed. Applied Statistics for the Behavioral Sciences. Houghton Mifflin Company: Boston; New York.

Holzemer, W. (1994). The impact of nursing care in Latin America and the Caribbean: A focus on outcomes. Journal of Advanced Nursing, 20, 5-12.

Huang, C., Wu, S, Jeng, C., Lin, L. (2004). The efficacy of a home based nursing program in diabetic control of elderly people with diabetes mellitus living alone. Public Health Nursing, 21, 49-56.

Huffman, M. (2004). Patient Outcomes what does it all mean? Home Healthcare Nurse, $22(1), 22-27$

Jonathan, R., Longest, B., \& Darr, K. (1992). Managing health services organizations. Health Professions Press, London England.

Inglis, S., McLennan, S., Dawson, A., Birchmore, L., Horowitz, J., Wilkinson, D., \& Stewart, S. (2004). A new solution for an old problem? Effects of a nurse led multidisciplinary home based intervention on readmission and mortality in patients with chronic atrial fibrillation. Journal of Cardiovascular Nursing, 19, $118-127$.

Intrator, O.\& Berg, K. (1998). Benefits of home health care after inpatient rehabilitation for hip fracture: Health service use by medicare beneficiaries. Archives of Physical Medicine and Rehabilitation, 79, 1195-1199.

Kane, R. (1999) Examining the efficiency of home care. Journal of Aging and Health, 11 (3), 322-339. 
Kane, R. (1999). Goals of home care: Therapeutic, compensatory, either or both? Journal of Aging and Health, 11(3), 299-321.

Kane, R. \& Kane, R. (1987). Long term care: Principles, programs, and policies. New York: Springer.

Kearney, M., York, R., \& Deatrick, J. (2000). Effects of home visits to vulnerable young families. Journal of Nursing Scholarship, 32, 369-376.

Keepnews, D., Capitman, J., \& Rosati, R. (2004). Measuring patient level clinical outcomes of home health care. Journal of Nursing Scholarship, 36(1), 79-85.

Kerlinger, F. \& Lee, H. (Eds.) (2000). Foundations of behavioral research $4^{\text {th }}$ Edition. Thomas Learning Inc.

Ketelaars, C., Abu-Saad, H., Halfens, R., Schlosser, M., Mostert, R., \& Wouters, E. (1998). Effects of specialized community nursing car in patients with chronic obstructive pulmonary disease. Heart and Lung, The Journal of Acute and Critical Care, 27, 109-120.

Kitzman, H., Olds, D., Henderson, C., Hanks, C., Cole, R., \& Tatelbaum, R. (1997). Effect of prenatal and infancy home visitation by nurses on pregnancy outcomes, childhood injuries, and repeated childbearing.: A randomized clinical trial. Journal of the American Medical Association, 278, 644-652.

Koniak-Griffin, D., Anderson, N., Verzemnieks, I., \& Brecht, M. (2000). A public health nursing early intervention program for adolescent mothers: Outcomes from pregnancy through 6 weeks postpartum. Nursing Research. 49, 130-138.

Kramer, A., Kowalsky, J., Lin, M. Grigsby, J., Hughes, R., \& Steiner, J. (year). Outcome and utilization differences for older persons with stroke in HMO and fee for 
service systems. Journal of the American Geriatrics Society, 48(7), 726-734

Lee, R., Graydon, J., \& Ross, E. (1991). Effects of psychological well being, physical status, and social support on oxygen dependent COPD patient's level of functioning. Research in Nursing \& Health, 14, 323-328.

Leidy, N. (1994). Functional status and the forward progress of merry go rounds: Toward a coherent analytical framework. Nursing Research, 43, 196-202.

Lieberman, D. \& Lieberman, D. (2005). Rehabilitation following stroke in patients aged 85 and older. Journal of Rehabilitation Research and Development, 42(1), 47-54.

Li, H., Morrow-Howell, N., \& Proctor, E. (2004). Post acute home care and hospital readmission of elderly patients with congestive heart failure. Health and Social Work, 29, 275-283.

Lowery, L. \& Brecht, P. (1998). Effects of comprehensive care on pregnancy outcomes. Applied Nursing Research, 11, 55-61.

Madigan, E., \& Fortinsky, R. (2000). Additional psychometric evaluation of the outcomes and assessment information set. Home Health Care Services Quarterly, $18,49-62$.

Madigan, E., Tullai-McGuinness, S., \& Fortinsky, R. (2002). Oasis is here to stay. Caring, 6, 6-9.

Martensson, J., Karlsson J., \& Fridlund, B. (1998). Female patients with congestive heart failure and their conception of the life situation. Journal of Advanced Nursing, $28(6), 1216-1224$

Martensson, J., Karlsson J., \& Fridlund, B. (1997). Male patients with congestive heart failure and their conception of the life situation. Journal of Advanced Nursing, 


$$
25,579-586
$$

Mayberry, L.\& Gennaro, S. (2001). A quality of health outcomes model for guiding obstetrical practice. Journal of Nursing Scholarship, 33, 141-146.

Mayer, C., Ergina, P., Morin, J., \& Gold, S.(2003). Self reported functional status as a predictor of coronary artery bypass graft surgery outcome in elderly patients. Canadian Journal of Cardiology, 19, 140-144.

McCorkle, R., Benoliel, J., Donaldson, G., Georgiadou, F., Moinpour, C., \& Goodell, \& B. (1989). A randomized clinical trial of home nursing care for lung cancer patients. Cancer, 15, 1375-1382.

McCorkle, R., Strumpf, N., Nuamah, I., Adler, D., Cooley, M., Jepson, C., Lusk, E., \& Torosian, M. (2000). A specialized home care intervention improves survival among older post surgical cancer patients. Journal of American Geriatrics Society, 48, 1707-1713.

Meis, M. (2001). Home Care: Where the Elderly and Chronic Issues Meet. Home Health Care Management and Practice, 13(6), 458-461.

Mertler, C. \& Vannatta, R. (2005). Advanced and Multivariate Statistical Methods. $3^{\text {rd }}$ ed Pyrczak Publishing: Glendale, Ca.

Mezey, M., \& McGivern, D., (1999). Nurse, nurse practitioners: Evolution to advances practice. Springer Publishing Co. New York, NY.

Mitchell, P. \& Lang, N. (2004). Framing the problem of measuring and improving healthcare quality. Medical Care, 42(2), 4-11.

Mitchell, P., Ferketich, S., \& Jennings, B. (1998). Quality health outcomes model. Imagethe Journal of Nursing Scholarship, 30(1), 43-46. 
Mithal, M., Mann, W.C., \& Granger, C. (2001). The role of coronary heart disease in Functional limitation in community dwelling elders. Physical and Occupational Therapy in Geriatrics, 19(3), 33-46.

Mithal, M., Mann, W.C., \& Stone, J.H. (2001). Functional limitation and disability associated with congestive heart failure. Physical and Occupational Therapy in Geriatrics, 18(3), 45-56.

Moody, L., McCormick, K., \& Williams, A., (1991). Psychophysiologic correlates of quality of life in chronic bronchitis and emphysema. Western Journal of Nursing Research, 21, 62-70.

Moore, S. (1995). A comparison of women's and men's symptoms during home recovery after coronary artery bypass surgery. Heart and Lung, 24(6), 495-501.

Mossey, J., \& Shapiro, E. (1982). Self rated health: A predictor of mortality among the elderly. American Journal of Public Health, 72, 800-807.

Munro, B. (2005). Statistical methods for health care research, $5^{\text {th }}$ ed. Lippencott, Williams \& Wilkins: Chestnut Hill, Massachusetts.

Murkofsky, R., Phillips, R., McCarthy, E., Davis, R., \& Hamel, M. (2003). Length of stay in home care before and after the 1997 Balanced Budget Act. Journal of the American Medical Association, 289(21), 2841-2848.

National Center for Health Statistics (2005). MMWR: Morbidity and Mortality Weekly Repor,. 54(4), 100-105.

National Committee for Quality Assurance (2005). The state of health care quality. Washington, DC.

Nelson, R. (2004). Measuring outcomes in home health care: beyond the OASIS data set. 
Home Health Care Management and Practice, 16, 200-205.

Nunnally, J. (1978) Psychometric theory. McGraw-Hill: New York.

Outcome and Assessment Information Set. (1998). Implementation Manual. Department of Health and Human Services, Health Care Financing Administration.

Olds, D., Robinson, J., O’Brien, R., Luckey, D., Pettitt, L., Henderson, C., Ng, R., Sheff, R., Korfmacher, J., Hiatt, S., \& Talmi, A. (2002). Home visiting by paraprofessional and by nurses: A randomized, controlled trial. Pediatrics, $100(3), 486-496$.

Olds, D. (2002). Prenatal and infancy home visiting by nurses: From randomized trials to community replication. Prevention Science, 3(3), 153-172.

Patrick, D., Kinne, S., Engelberg, R., \& Pearlman, R. (2000). Functional status and perceived quality of life in adults with and without chronic conditions. Journal of Clinical Epidemiology, 53(8), 779-785.

Payne, S., Thomas, C., Fitzpatrick, T., Abdel-Rahman, A., \& Kayne, H. (1998).

Determinants of home health visits length: Results of a multisite prospective study. Medical Care, 36, 1500-1514.

Pierce, C. (1998). Relationship of dyspnea to functional status and functional capacity in non small cell lung cancer surgical resection patients. University of Nebraska Medical Center **PhD.

Portillo, C. \& Schumacher, K. (1998). Graduate program: Advanced practice nurses in the home. Clinical Issues, Advanced Practice in Acute Critical Care, 9(3), 355361.

Radwin, L. (1989) Cues and strategies used in the diagnosis of pain conditions. In 
Classifications of Nursing Diagnosis: Proceedings of the Eight Conference

(Carroll-Johnson,R. ed), Lippincott, Philadelphia, 381-387.

Radwin, L. (1995). Knowing the patient: a process model of individualizing interventions. Nursing Research, 44, 364-370.

Radwin, L., \& Fawcett, J. (2002). A conceptual model based program of nursing research: retrospective and prospective applications. Journal of Advanced Nursing, 40(3) 355-360.

Redeker, N. \& Brassard, A. (1996). Health patterns of cardiac surgery clients using home health care nursing services. Public Health Nursing, 13(6), 394-403.

Reider, E., \& Olds, D. (June 2003). Developing, Testing, and Replicating the nurse family partnership. Paper presented at the Society for Prevention Research $11^{\text {th }}$ Annual Meeting. Research to Policy, Washington, DC. June 12-14, 2003.

Rich, M., Beckham, V., Wittenberg, C., Leven, C., Freedland, K., \& Carney, R. (1995). A Multidisciplinary intervention to prevent the readmission of elderly patients with congestive heart failure. The New England Journal of Medicine, 333(18), 1190-1195.

Rigler, S., Studenski, S., Wallace, D., Reker, D., \& Duncan, P. (2002). Co-morbidity adjustment for functional outcomes in community dwelling older adults. Clinical Rehabilitation, 16, 420-428.

Russell, S., McNeer, F., \& Higginbotham, M. (1998) Exertional dyspnea in heart failure: A symptom unrelated to pulmonary function at rest or during exercise. American Heart Journal, 135(3), 398-405.

Shaughnessy, P. \& Hittle, D. (2002). The overview of risk adjustment and outcome 
measures for home health agency OBQI reports: Highlights of current approaches and outline of planned enhancements. Center for Health Services Research. University of Colorado Health Sciences Center: Denver, Colorado. Sienkiewicz, J. (2004). The auality network adverse event benchmarking project: A New Jersey perspective. Home Health Care Management and Practice, 16(4), 280-285.

Shelkey, M. \& Wallace M. (1998). Katz index of independence in activities of daily living. TheHartford Institute for Geriatric Nursing, 2.

Shepard, R. (1997). Impact of the aging on major physiological systems at rest and during submaximal and maximal exercise. In R.J.Shepard (Ed.), Aging, Physical Activity, and Health, 57-138.

Smith, C., Cowan, C., Senseinig, A., \& Catlin, A. (2005). Health spending growth slows in 2003. Health Affairs, 24(1), 185-194.

Stewart, S., Morley, J., \& Horowitz, J. (2000). The addition of a home visit by a cardiac nurse to usual multidisciplinary care reduced deaths and readmissions in patients with chronic congestive heart failure. Evidence Based Nursing, 56(3), 1077-1083.

Stewart, S., Vandenbroek, A., Pearson, S., \& Horowitz, J. (1999). Prolonged Beneficial effects of a home based intervention on unplanned readmissions and mortality among patients with congestive heart disease. Archives of Internal Medicine, 159, $257-261$.

Utterback, Karen. (2001). Prospective payment comes to medicare home health: How will it affect your practice? American Journal of Nursing, 101(7), 59-61.

Wang, L., Van Belle, G., Kukull, W., \& Larson, E. (2002). Predictors of functional 
change: A longitudinal study of non demented people aged 65 and older. American Geriatrics Society, 50, 1525-1534.

Weaver, F., Hughes, S., Orit, A., Wixson, R., Manheim, L., Fulton, B., \& Singer, R. (2003). Comparison of two home care protocols for total joint replacement. Journal of American Geriatric Society, 51, 223-228.

Wensing, M., Vingerhoets, E., \& Grol, R. (2001). Functional status, health problems, age and comorbidity in primary care patients. Quality of Life Research, 10(2), 141148.

Williams, M., Fleg, J., Ades, P., Chaitman, B., Miller, N., Mohiuddein, S., Ockene,I., Taylor, B., \& Wenger, N. (2002). Secondary prevention of Coronary Heart Disease in the elderly (With emphasis on patients $>=75$ years of age): An American heart association scientific statement from the council on clinical cardiology subcommittee on exercise, cardiac rehabilitation, and prevention. Circulation, 105(14), 1735-1743.

Zhu, C. (2004). Effects of the balanced budget act on medicare home health utilization. Journal of the American Geriatric Society, 52(6), 989-994. 
Appendix A: Chart Abstraction-Admission

Patient code:

(M0030) Start of care

(M0066) Birth date

(M0069) Gender:

(M0140) Ethnicity: 1-7

(M0150) Payment: 1-11

(M0175) Which inpatient facility dc'd 1-6

(M0220) Conditions prior to admit 1-9:

(M0230.M0240) Primary diagnosis (ICD-9)

Severity code $0-4$

Secondary diagnosis (ICD-9)

Severity code $0-4$

(M0250) Therapies 1-4

(M0260) Prognosis 1-3:

(M0270) Rehab prognosis 1-3:

(M0280) Life expectancy 0-1:

(M0290) High risk factors 1-6:

(M0300) Current Residence 1-5:

(M0340) Patient lives with 1-6:

(M0350) Assisting patient 1-5:

(M0360) Primary caregiver 0-6:

(M0370) How often receives help 1-7:

(M0380) Type of caregiver 1-8: 
\# of meds

Height /weight on admit

(M0390) Vision 0-2:

(M0400) Hearing 0-4:

(M0410) Speech 0-5:

(M0420) Pain 0-3:

(M0430) Intractable pain 0-1:

(M0445) Pressure ulcer 0-1:

(PU1) Pressure ulcer stage 1 : how many:

(PU2) Pressure ulcer stage 2 : how many

(PU3) Pressure ulcer stage 3: how many

(PU4) Pressure ulcer stage 4: how many

(M0470) Stasis \#

(SU) location

(M0484) Surgical wound \#

(SI) location

(M0490) Dsypnea 0-4:

(M0500) Resp treatments 1-4:

(M0510) UTI last 14 days $0-4$ :

(M0520) Incontinence /Catheter 0-2:

(M0530) When does incontinence occur 0-2:

(M0540) Bowel incontinence 0-7:

(M0550) Ostomy 0-2:

(M0560) Cognitive Functioning 0-4:

(M0570) Confused 0-5:

(M0580) Anxious 0-4: 
(M0590) Depressed 1-6:

(M0610) Behaviors 1-7:

(M0620) Frequency of behavioral problems 0-5:

(M0640) Grooming 0-3: prior

Current Recoded \% $0=0 \%=\overline{100 \% \quad 1=33 \%=66 \%} \quad 2=66 \%=\overline{33 \%} \quad 3=100 \%=0 \%$ Reversed

(M0650) Ability to dress upper body 0-3

Current Recoded \% Reversed

$0=0 \%=\overline{100 \% \quad 1=33 \%=66 \%} \quad 2=66 \%=\overline{33 \%} \quad 3=100 \%=0 \%$

(M0660) Ability to dress lower body 0-3

Current Recoded \% $0=0 \%=100 \% \quad 1=33 \%=66 \% \quad 2=66 \%=\overline{33 \%} \quad 3=100 \%=0 \%$ Reversed

(M0670) Bathing 0-5

Current Recoded \% Reversed

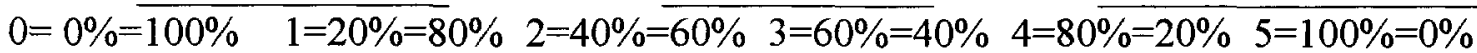

(M0680) Toileting 0-4

Current Recoded \% Reversed $0=0 \%=\overline{100 \%} \quad 1=25 \%=75 \% \quad 2=50 \%=50 \% \quad 3=75 \%=25 \% \quad 4=100 \%=0 \%$

(M0690) Transferring 0-5

Current Recoded \% Reversed $0=0 \%=100 \% \quad 1=20 \%=80 \% \quad 2=40 \%=60 \% \quad 3=60 \%=40 \% \quad 4=80 \%=20 \% \quad 5=100$ (M0700) Ambulation 0-5

Current Recoded \% Reversed $0=0 \%=\overline{100 \%} \quad 1=20 \%=80 \% \quad 2=40 \%=60 \% \quad 3=60 \%=40 \% \quad 4=80 \%=20 \% \quad 5=100$

(M0710) Feeding/Eating 0-5

Current Recoded \% Reversed

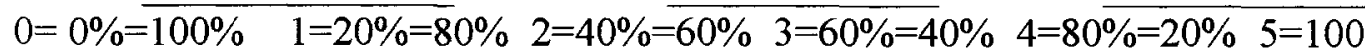
(M0720) Planning or preparing meal 0-2

Current Recoded \% $0=0 \%=100 \% \quad 1=50 \%=50 \% \quad 2=100 \%=0 \%$ Reversed

(M0730) Transportation 0-2

Current Recoded \% $0=0 \%=100 \% \quad 1=50 \%=50 \% \quad 2=100 \%=0 \%$ Reversed 
(M0740) Laundry 0-2

Current Recoded $\%$

$0=0 \%=100 \% \quad 1=50 \%=50 \% \quad 2=100 \%=0 \%$ Reversed

(M0750) Housekeeping 0-4

Current Recoded \% Reversed

$0=0 \%=100 \% \quad 1=25 \%=75 \% \quad 2=50 \%=50 \% \quad 3=75 \%=25 \% \quad 4=100 \%=0 \%$

(M0760) Shopping 0-3

Current Recoded \% $0=0 \%=\overline{100 \%} \quad 1=33 \%=66 \% \quad 2=66 \%=33 \% \quad 3=100 \%=0 \%$ Reversed

(M0770) Telephone 0-5

Current Recoded \% Reversed

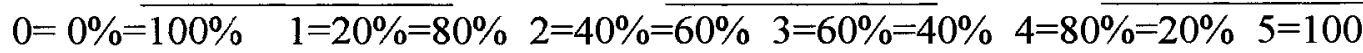

(M0780) Medications 0-2

Current Recoded \% $0=0 \%=100 \% \quad 1=50 \%=50 \% \quad 2=100 \%=0 \%$ Reversed

(M0790) Inhaled medication 0-2

Current Recoded \%

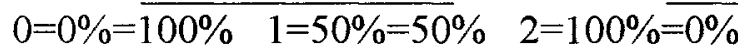
Reversed

(M0800) Injectable medications

Current Recoded \% Reversed

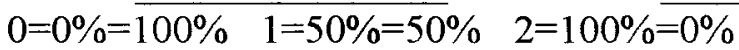

(M0810) Manage equipment 0-4

Current Recoded \% Reversed $0=0 \%=100 \% \quad 1=25 \%=75 \% \quad 2=50 \%=50 \% \quad 3=75 \%=25 \% \quad 4=100 \%=0 \%$

(M0820) Caregiver manage equipment 0-4 Current Recoded \% Reversed $0=0 \%=100 \% \quad 1=25 \%=75 \% \quad 2=50 \%=50 \% \quad 3=75 \%=25 \% \quad 4=100 \%=0 \%$ 
Appendix B: Chart Abstraction-discharge

Patient code:

(M0030) Start of care:

(M0066) Birth date

(M0069) Gender:

(M0250) Therapies 1-4

(M0280) Life expectancy 0-1:

(M0290) High risk factors 1-6:

(M0300) Current Residence 1-5:

(M0340) Patient lives with 1-6:

(M0350) Assisting patient 1-5:

(M0360) Primary caregiver 0-6:

(M0370) How often receives help 1-7:

(M0380) Type of caregiver 1-8:

(M0410) Speech 0-5:

(M0420) Pain 0-3:

(M0430) Intractable pain 0-1:

(M0445) Pressure ulcer 0-1:

(PU1) Pressure ulcer stage 1 : how many

(PU2) Pressure ulcer stage 2 : how many

(PU3) Pressure ulcer stage 3: how many

(PU4) Pressure ulcer stage 4: how many

(M0470) Stasis \# 
(SU) location

(M0484) Surgical wound \#

(SI) location

(M0490) Dsypnea 0-4:

(M0500) Resp treatments 1-4:

(M0510) UTI last 14 days 0-4:

(M0520) Incontinence /Catheter 0-2:

(M0530) When does incontinence occur 0-2:

(M0540) Bowel incontinence 0-7:

(M0550) Ostomy 0-2:

(M0560) Cognitive Functioning 0-4:

(M0570) Confused 0-5:

(M0580) Anxious 0-4:

(M0590) Depressed 1-6:

(M0610) Behaviors 1-7:

(M0620) Frequency of behavioral problems 0-5:

(M0640) Grooming 0-3: prior

\begin{tabular}{|c|c|}
\hline & Reversed \\
\hline
\end{tabular}

(M0650) Ability to dress upper body 0-3

Current

Recoded \%

$0=0 \%=100 \% \quad 1=33 \%=66 \% \quad 2=66 \%=33 \% \quad 3=100 \%=0 \%$

Reversed

(M0660) Ability to dress lower body 0-3
Current
Recoded \%

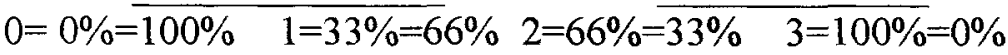
Reversed

(M0670) Bathing 0-5

Current

Recoded \%

Reversed

$0=0 \%=100 \% \quad 1=20 \%=80 \% \quad 2=40 \%=60 \% \quad 3=60 \%=40 \% \quad 4=80 \%=20 \% \quad 5=100 \%=0 \%$ 
(M0680) Toileting 0-4

Current Recoded \% Reversed

$0=0 \%=100 \% \quad 1=25 \%=75 \% \quad 2=50 \%=50 \% \quad 3=75 \%=25 \% \quad 4=100 \%=0 \%$

(M0690) Transferring 0-5

Current

Recoded \%

Reversed

$0=0 \%=100 \% \quad 1=20 \%=80 \% \quad 2=40 \%=60 \% \quad 3=60 \%=40 \% \quad 4=80 \%=20 \% \quad 5=100$

(M0700) Ambulation 0-5

Current

Recoded \%

Reversed

$0=0 \%=100 \% \quad 1=20 \%=80 \% \quad 2=40 \%=60 \% \quad 3=60 \%=40 \% \quad 4=80 \%=20 \% \quad 5=100$

(M0710) Feeding/Eating 0-5

Current

Recoded \%

Reversed

$0=0 \%=100 \% \quad 1=20 \%=80 \% \quad 2=40 \%=60 \% \quad 3=60 \%=40 \% \quad 4=80 \%=20 \% \quad 5=100$

(M0720) Planning or preparing meal 0-2

Current Recoded \%

Reversed

$0=0 \%=100 \% \quad 1=50 \%=50 \% \quad 2=100 \%=0 \%$

(M0730) Transportation 0-2

Current Recoded \%

$0=0 \%=100 \% \quad 1=50 \%=50 \% \quad 2=100 \%=0 \%$ Reversed

(M0740) Laundry 0-2

Current Recoded \% Reversed $0=0 \%=100 \% \quad 1=50 \%=50 \% \quad 2=100 \%=0 \%$

(M0750) Housekeeping 0-4

Current Recoded \% Reversed $0=0 \%=100 \% \quad 1=25 \%=75 \% \quad 2=50 \%=50 \% \quad 3=75 \%=25 \% \quad 4=100 \%=0 \%$

(M0760) Shopping 0-3

Current Recoded \% Reversed

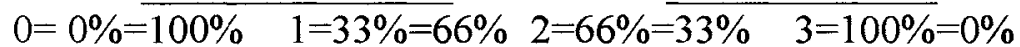

(M0770) Telephone 0-5

Current Recoded \% Reversed $0=0 \%=100 \% \quad 1=20 \%=80 \% \quad 2=40 \%=60 \% \quad 3=60 \%=40 \% \quad 4=80 \%=20 \% \quad 5=100$

(M0780) Medications 0-2

Current Recoded \% $0=0 \%=\overline{100 \% \quad 1=50 \%=50 \%} \quad 2=100 \%=0 \%$ Reversed

(M0790) Inhaled medication 0-2 
Current

Recoded \%

Reversed

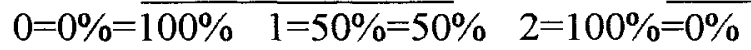

(M0800) Injectable medications

Current

Recoded \%

Reversed

$0=0 \%=100 \% \quad 1=50 \%=50 \% \quad 2=100 \%=0 \%$

(M0810) Manage equipment 0-4

Current Recoded \% Reversed

$0=0 \%=100 \% \quad \mathrm{l}=25 \%=75 \% \quad 2=50 \%=50 \% \quad 3=75 \%=25 \% \quad 4=100 \%=0 \%$

(M0820) Caregiver manage equipment 0-4

Current Recoded \% Reversed

$0=0 \%=\overline{100 \%} \quad 1=25 \%=75 \% \quad 2=50 \%=50 \% \quad 3=75 \%=25 \% \quad 4=100 \%=0 \%$

(M0830) Emergent Care: 0-3

(M0840) Emergent Care Reason 1-9

(M0870) Discharge disposition 1-4

(M0880) After care 1-3

(M0900) Date of last home visit

Reason for discharge:

Death, Lack of progress Admitted to hospital

Transferred to another Organization

Patient moved out of area

No further care needed

Admitted to SNF

Physician request

Family/caregiver assumed responsibility

Patient refused services

Home situation has become unsafe

Other

\# of visits made

Disciplines and \# of visits

PT

RN

OT

MSW ST

HHA 
Appendix C: Consent from the President of Excel Home Health 


\section{EXCEL HOME HEALTH}

July 6,2005

To Whom It May Concern:

Marita McGoldrick has been granted permission to collect and study the data from patient charts, at Excel Home Health, from January 1, 2003 to December 31, 2004. Information recorded from the chart review will be done in such a manner that the subjects cannot be identified directly or through identifiers linked to subjects. Ms. McGoldrick has agreed that anonymity will be maintained, individual names and characteristics will not be presented, and data analysis expressed group information, not individual information.

Per my understanding there is no perceived potential physical, psychological, or social risks to the subjects in this study.

Sincerely,

\section{Sri Gopal}

President \& CEO Excel Home Health 